\title{
LA EVOLUCIÓN POLÍTICO-CONSTITUCIONAL DE CHILE 1976-2005
}

\author{
The political-constitutional evolution of Chile 1976-2005
}

\author{
Humberto Nogueira Alcalá ${ }^{1}$ \\ Profesor Titular de Derecho Constitucional, \\ Universidad de Talca, Chile. \\ nogueira@utalca.cl
}

RESUM EN: En el presente trabajo se realiza un análisis descriptivo de la evolución política y constitucional de Chile en el periodo 1976-2005, una vez ya desarrollado el Golpe de Estado encabezado por las Fuerzas Armadas, considerando la institucionalización del regimen autoritario militar, el establecimiento de la Constitución de 1980 y la evolución del régimen hasta 1988, fecha en que el Jefe de Estado, General Augusto Pinochet pierde el plebiscito y debe negociar con la disidencia, una transición pactada hacia la democracia que incluye un importante paquete de reformas constitucionales. Se continúa con la evolución del sistema institucional desde la instalación de los gobiernos democráticos desde marzo de 1990 hasta 2005, como las principales reformas constitucionales del periodo que concluye con la gran reforma de 2005, que elimina los últimos enclaves autoritarios de la Constitución. Se analizan el sistema de gobierno, de partidos y el sistema electoral, la evolución del sistema de jurisdicción constitucional y el sistema de derechos fundamentales.

PA LA BRAS CLAVE: Evolución Constitucional de Chile. Derecho Constitucional. Régimen político. Reformas constitucionales. Derechos fundamentales. Sistema de partidos políticos. Sistema electoral. Sistema de jurisdicción constitucional.

1 El autor es Doctor en Derecho por la Universidad Católica de Lovaina La Nueva, Bélgica. Diplomado en Ciencias del Desarrollo con mención en Ciencia Política, ILADES. Profesor Titular de Derecho Constitucional y Director del Centro de Estudios Constitucionales de Chile. Miembro A sociado de la Academia Internacional de Derecho Comparado. Presidente de la A sociación Chilena de Derecho Constitucional y Vicepresidente del Instituto Iberoamericano de Derecho Procesal Constitucional. Recibido este artículo el 30 de junio de 2008, siendo aprobado el 30 de octubre de 2008. 
ABSTRACT: The present paper is an analysis of the political and constitutional developments in Chile in the period 1976-2005, and once developed the coup d'état led by the Armed Forces, considering the institutionalization of authoritarian military regime, the establishment of the Constitution 1980 and the evolution of the regime until 1988, when the Head of State, General Augusto Pinochet lost the plebiscite and must negotiate with the dissidents, agreed on a transition to democracy that includes a substantial package of constitutional reforms. It follows with the development of the institutional system since the installation of democratic governments from M arch 1990 until 2005, as the major constitutional reforms for the period ending with the great reform of 2005, which removes the last authoritarian enclaves of the 1980 Constitution. We analyze the system of government, political parties and the electoral system, the evolution of the system of constitutional jurisdiction and the system of fundamental rights.

KEY WORDS: Constitutional Evolution of Chile. Constitutional law. Presidencial Government System. Constitutional reforms. Political party system. Electoral System. Fundamental rights. Defence of the Constitution. Constitutional jurisdiction. Constitutional control.

\section{EL PERIODO 1976-1988: LA INAUGURACIÓN, INSTITUCIONALIZACIÓN Y CONSOLIDACIÓN DEL RÉGIMEN AUTORITARIO MILITAR}

El golpe de Estado de 11 de septiembre de 1973 desarrollado en forma orgánica por las tres ramas de las Fuerzas A rmadas, a las que se integró a Carabineros (policía uniformada), puso fin a una etapa institucional de la república democrática chilena desarrollada bajo el imperio de la Constitución de 1925, la que había entrado en una fuerte polarización ideológica y un bloqueo institucional y político, además de una fuerte crisis económica y social, elementos todos que contribuyeron a la caída del régimen democrático, elemento que no corresponde analizar en este trabajo.

El régimen autoritario en su modalidad burocrático militar que se instala en Chile, se estructura en base a una Junta de Gobierno integrada por los respectivos comandantes en Jefe institucionales y el General Director de Carabineros, dentro de la cual el primus inter pares, es el comandante en jefe del Ejército General Augusto Pinochet Ugarte.

Dicha Junta de Gobierno asume el poder constituyente, legislativo y ejecutivo (Decreto Ley № 1 y Decreto Ley № 128). El poder judicial es respetado en la medida que legítima con su conducta al régimen autoritario militar y tolera el atropello a los derechos humanos.

A I año 1976, ya se había concretado la etapa más dura de la política institucional del régimen militar de eliminación de enemigos políticos mediante ejecuciones extrajudiciales, desapariciones forzadas y tortura, aunque dicha política se mantuvo por 
varios años más, siendo la DINA y luego la CNI los grupos encargados de implementar dicha política.

Ya inaugurado el régimen autoritario militar, entra en una etapa de consolidación e institucionalización.

El poder se concentra progresivamente en el general Pinochet y su principales colaboradores que luego pasa a ocupar el cargo de "Presidente de la República".

El General Pinochet expresaba con claridad su voluntad de permanecer en el poder y de realizar un cambio radical de la sociedad chilena en declaración a la Revista Ercilla en agosto de 1975: “El régimen actual está llamado a durar posiblemente una generación. Esta lucha puede esperar un siglo si es necesario porque conviene dar nacimiento a un espíritu público nuevo que haga imposible el retorno al juego político anterior. El proceso iniciado el 11 de septiembre de 1973 es un camino sin retorno".

En base al férreo control político y policial se modifican profundamente las bases sociales y económicas a través de un modelo neoliberal, donde la autoridad económica gubernamental opera sin contrapeso alguno.

El régimen autoritario militar se desarrolla con el apoyo básico del movimiento gremialista dirigido por Jaime Guzmán y la derecha política, que serán el grupo de apoyo e implementación de las políticas durante todo el período autoritario, y en el ámbito económico, por el grupo de los "chicagos boys" y los círculos empresariales que se encuentran favorecidos por el modelo en sus demandas corporativas por el proceso de privatización y desregulación económica.

El alto nivel de personalización del poder político en el General Pinochet es débilmente contrapesada por el procedimiento de toma de decisiones en la Junta de Gobierno, donde las decisiones legislativas y constituyentes deben adoptarse por unanimidad.

El objetivo central del régimen será la estructuración de una “democracia autoritaria y protegida" con tutela militar y pluralismo limitado. ${ }^{2}$

La Junta de Gobierno M ilitar que había designado el 24 de septiembre de 1973 una comisión encargada de preparar un anteproyecto de Constitución, la que quedó oficializada por el Decreto Supremo № 1064 de 25 de octubre de 1973, ${ }^{3}$ sufrirá una crisis por la renuncia en marzo de 1977 de los profesores de derecho constitucional Alejandro Silva Bascuñán y Enrique Evans de la Cuadra por considerar que la Junta de Gobierno no

2 Ver Huneeus, Carlos (2000). El régimen de Pinochet. Editorial Sudamericana, Santiago, Chile. Cañas Kirly, Enrique. Proceso Político en Chile. 1973-1990. Ed. Andrés Bello. Santiago, Chile. A rRIAgada, Genaro (1998). Por la razón o la fuerza, Chile bajo Pinochet. Ed. Sudamericana. Santiago, Chile. VIAL, Gonzalo (Ed.) (1998). A nálisis crítico del régimen militar. Universidad Finis Terrae. Santiago, Chile.

3 Publicado en Diario Oficial № 28.699 del 12 de noviembre de 1973. 
estaba orientada a restablecer el régimen democrático, sino a consolidar un régimen autoritario, al dictar el Decreto Ley 1.697 que disuelve los partidos políticos que no formaban parte del gobierno del Presidente Allende. En mayo del mismo año renuncia también el profesor Jorge Ovalle Q uiroz. En su reemplazo, en junio de 1977, se nombrarán a doña Luz Bulnes A. y a los señores Raúl Bertelsen R., y Juan de Dios Carmona P.

Dicha Comisión originalmente denominada "Constituyente" y más tarde "de Estudios de la Nueva Constitución Política del Estado" funcionó entre el 24 de septiembre de 1973 y el 5 de octubre de 1978, periodo dentro del cual realizó 417 sesiones, en las cuales debatió, aprobó y redactó un anteproyecto de Constitución Política.

La elaboración de la parte dogmática de la Constitución se desarrolló hasta marzo de 1978, fecha esta última, en la que se inicia el estudio y aprobación de la parte orgánica de la Constitución, vale decir, a la estructuración del poder estatal.

Constituye una etapa importante en la orientación de los trabajos de la Comisión el memorandum que le dirige el 10 de noviembre de 1977, el General Augusto Pinochet, quien a ese momento ya había asumido el título de Presidente de la República, en cuyo punto cuarto llama a la Comisión a configurar una "nueva democracia, cuyos caracteres más importantes he sintetizado bajo los términos de autoritaria, protegida, integradora, tecnificada y de auténtica participación social". En el punto quinto del memorandum subraya ciertas ideas básicas que plasman los criterios políticos-institucionales que orientan al gobierno militar, entre las que destacan la creación de un poder de seguridad que contemple la función de las Fuerzas A rmadas en su tarea de garantizar la supervivencia del Estado y los principios básicos de la institucionalidad; el afianzamiento del sistema presidencial chileno a través de una autoridad fuerte, dotada de facultades necesarias para conducir la política económica y social al margen de indebidas interferencias parlamentarias; como equilibrio frente al poder presidencial, un conjunto de eficaces sistemas de control que eviten los excesos; la proscripción legal de la difusión y acción de doctrinas, grupos y personas de inspiración totalitaria; la creación de una instancia técnica independiente destinada a manejar la política económica y social al margen de acciones demagógicas, radicada en el Banco Central; el establecimiento de sistemas electorales que impidan a los partidos políticos convertirse en conductores monopólicos de la participación ciudadana; la revisión del sistema de elección del Presidente de la República para evitar que llegue al poder una persona con una votación minoritaria; una modificación substancial de la composición del futuro parlamento, incluyendo una cuota de legisladores por derecho propio o por designación; la profesionalización de la administración pública; la preservación de la autonomía de los cuerpos intermedios; el establecimiento de normas que impidan la intromisión de los grupos políticos en la generación y funcionamiento de las entidades gremiales, sindicales y sociales; y el robustecer constitucionalmente las bases de una estructura económico-social que refuercen la libertad, la libre iniciativa económica y el derecho de propiedad privada de los bienes de producción como reglas generales. 
La Comisión presenta el 17 de agosto de 1978 un informe con las ideas básicas y un anteproyecto articulado, constituido por 123 disposiciones permanentes y 11 transitorias, las cuales recogen las ideas esbozadas por el informe o memorandum que había enviado el General Pinochet con algunas matizaciones.

El anteproyecto fue entregado al Jefe de Estado, el cual lo remite al Consejo de Estado ${ }^{4}$ para su estudio, organismo integrado por personas de la confianza del régimen militar, el cual se negó a integrar el ex Presidente Eduardo Frei Montalva.

El 31 de octubre de 1978, el Jefe de Estado solicitó al Consejo de Estado su opinión sobre el anteproyecto de Constitución Política de la República que había elaborado la Comisión de Estudios de la Nueva Constitución Política de la República. El estudio por parte del Consejo de Estado se efectuó entre noviembre de 1978 y julio de 1980 en 57 sesiones plenarias.

El Consejo de Estado formuló un llamado para presentar observaciones y sugerencias a la ciudadanía, recibiendo aproximadamente 150 indicaciones.

El Consejo de Estado elaboró un antepoyecto con diferencias respecto del preparado por la Comisión anteriormente señalada, el cual fue acordado en sesión del 1o de julio de 1980, con opiniones disidentes y votos de minoría.

El proyecto fue entregado al Jefe de Estado y a la Junta de Gobierno, por el Presidente del Consejo de Estado, el ex Presidente de la República, Jorge Alessandri Rodríguez, en una audiencia el 8 de julio de 1980. El proyecto del Consejo de Estado genera las normas que rigen un periodo transitorio de 5 años, desde el momento de la aprobación del texto hasta su plena vigencia.

La Junta de Gobierno en quien se encontraba radicado el Poder Constituyente, designó un grupo de trabajo integrado por el entonces Ministro del Interior, Sergio Fernández F.; la Ministra de Justicia, Mónica Madariaga G.; el Auditor General del Ejército, General Fernando Lyon; el Auditor General de la Armada, Almirante Aldo Montagna; el Auditor de la Fuerza Aérea, General Enrique Montero M.; el Auditor de Carabineros, Mayor Harry Gruenwald y el Secretario de Legislación de la Junta de Gobierno, M ario Duvauchelle R.,

La Junta de Gobierno, sobre la base de los dos anteproyectos de Constitución antes señalados y con el apoyo del grupo de trabajo, aprobó un proyecto de Constitución, sin que existan actas de los fundamentos de sus decisiones, optando por las disposiciones de algunos de los anteproyectos o modificando los artículos de éstos.

4 El Consejo de Estado había sido creado por el Decreto Ley 1.319, del 9 de enero de 1976, que dio vida al Acta Constitucional № 1. 
El proyecto definitivo aprobado por la Junta de Gobierno contenía el proyecto definitivo de Constitución permanente en 120 artículos y 29 disposiciones transitorias que regulan un período de transición hacia la plena vigencia del orden constitucional que se consideró adecuado establecerlo en 8 años, al cabo del cual se presentaría a ratificación popular el nombre del Jefe de Estado que de ser aprobado en plebiscito concretaría el segundo periodo de 8 años, con el apoyo de las herramientas de un Estado de Excepción especial para el período que se encontraban contenidas en la disposición 24 transitoria.

El texto aprobado por la Junta de Gobierno y firmado por los M inistros de Estado fue promulgado por el Decreto Ley № 3.464 el 8 de agosto de 1980. Con la misma fecha, se dicta el Decreto Ley № 3.465, el que convoca a plebiscito para que el texto sea ratificado por la aprobación ciudadana.

El 12 de agosto de 1980, el Presidente del Consejo de Estado y ex Presidente de la República, Jorge Alessandri Rodríguez, renuncia a la presidencia del Consejo de Estado, la cual debía mantenerse en reserva hasta el 12 de septiembre de 1980, día siguiente al plebiscito, si el proyecto gubernamental fuera aprobado; ella se hacía efectiva en virtud de los desacuerdos de Jorge Alessandri con la autonomía de las Fuerzas Armadas en relación al Presidente de la República, criterio que no comparte el ex Presidente.

El plebiscito fue convocado para el 11 de septiembre de 1980, el séptimo aniversario del golpe de Estado.

Se habilita para sufragar a los chilenos mayores de 18 años y los extranjeros mayores de dicha edad con residencia legal en Chile. La opción era votar sí o no respecto de la integridad del texto permanente de la Constitución, el periodo de transición y el mantenimiento del Presidente de la República y la Junta de Gobierno por un período de al menos nueve años más.

El plebiscito se concreta en un clima de ausencia de libertad de expresión, con los partidos políticos disueltos, sin registros electorales, sin apoderados de las opciones en juego en las mesas receptoras de sufragios y sin Tribunal que pudiera pronunciarse sobre la legitimidad y legalidad del acto plebiscitario. La regulación del plebiscito había agregado que los votos en blanco debían contabilizarse a favor de la alternativa de aprobación del texto propuesto por la Junta de Gobierno.

El resultado del plebiscito no sorprendió a nadie. La opción Sí obtuvo 4.121.067 y el $65,71 \%$ de los sufragios emitidos, a los cuales debe agregarse 83.812 votos en blanco con 1,33\% de los sufragios. La opción No obtuvo 1.893 .420 y $30,19 \%$ de los sufragios. Los votos nulos fueron 173.569 con un $2,77 \%$ de los sufragios emitidos. Se estimó la abstención en alrededor del 6\%.

El ex Presidente del Senado, Patricio Aylwin A., con otras 46 personalidades presentó un reclamo sobre ilegitimidad e ilegalidad del plebiscito aprobatorio de la Cons- 
titución pidiendo su anulación al Colegio Escrutador Nacional, el cual se basó en la falta de transparencia del escrutinio y la certificación de que las personas podían votar en dos o más mesas receptoras de sufragios, lo que establecía un clima de falta de garantías que distorsionaba el resultado electoral del plebiscito.

El Colegio Escrutador Nacional rechazó el reclamo señalando que no tenía competencia para pronunciarse en materia de calificación del plebiscito, sino solo para realizar el escrutinio nacional, sin perjuicio de lo cual realizó algunas consideraciones en apoyo del plebiscito realizado.

El texto aprobado fue promulgado por el Presidente de la República, General Augusto Pinochet U., con fecha 21 de octubre de 1980, el cual entraría en vigencia el 11 de marzo de 1981.

El texto aprobado consta de 14 capítulos en 120 artículos permanentes y 29 disposiciones transitorias. La estructura de la Carta Fundamental contempla como capítulo l: Bases de la Institucionalidad; Capítulo II: Nacionalidad y Ciudadanía; Capítulo III: Derechos y Deberes Constitucionales; Capítulo IV: Gobierno; Capítulo V: Congreso Nacional; Capítulo VI: Poder Judicial; Capítulo VII: Tribunal Constitucional; Capítulo VIII: Justicia Electoral; Capítulo IX: Contraloría General de la República; Capítulo X: Fuerzas Armadas, de Orden y Seguridad Pública; Capítulo XI: Consejo de Seguridad Nacional; Capítulo XII: Banco Central; Capítulo XIII: Gobierno y Administración Interior del Estado; Capítulo XIV: Reforma de la Constitución.

Durante el periodo 1981 hasta 1988 se caracterizará por un afianzamiento del modelo económico neoliberal y el mantenimiento de un gobierno autoritario militar con fuertes niveles de represión política y social, tratando de afianzar el modelo de democracia autoritaria y protegida.

A simismo, la disidencia se aglutina en movimientos sociales y se comienzan a rearticular las fuerzas políticas con mayor fuerza después de las explosiones sociales de 1983, la Alianza Democrática (AD), de centro izquierda, y el Movimiento Democrático Popular (M DP), de izquierda, integrado por algunos sectores socialistas y los comunistas.

Las diversas vertientes políticas, socialistas, democracia cristiana, los sectores socialdemócratas y pequeños sectores liberales democráticos (republicanos), humanistas, mapu, izquierda cristiana, verdes, como un partido instrumental que aglutina a sectores de diversas vertientes doctrinales (liberales, socialdemócratas y socialistas) que será el Partido por la Democracia, se reunirán en la Concertación Democrática y luego en la Concertación de Partidos por la Democracia, que irán tomando consistencia y acordarán una estrategia concertada de derrota política del régimen militar; buscarán desplazarlo pacíficamente en el plebiscito de 1988, en el cual la Constitución de 1980 había establecido la necesidad de consultar al pueblo sobre la mantención en el poder por otros ocho años del General Pinochet, acto que se realizará con registros 
electorales, un mayor clima de libertad de expresión, partidos políticos reconstituidos, mesas electorales y apoderados de todos los sectores políticos.

En este nuevo clima, la Concertación de Partidos por la Democracia logra una victoria en el plebiscito del 5 de octubre de 1988, el General Pinochet fue derrotado políticamente al obtener sólo un $43 \%$ de los votos que lo sostenían en su intención de permanecer en el poder por otros ocho años adicionales, lo que fue rechazado por el $54,7 \%$ de los votos y un $2,3 \%$ de blancos y nulos o abstención, todo lo cual abre el camino hacia la instalación de un gobierno democrático elegido por sufragio universal y un parlamento elegido, al menos mayoritariamente, en las elecciones competitivas de diciembre de 1989, ya que prácticamente un cuarto del Senado se integraría con senadores designados. Sin perjuicio de ello, el régimen militar había establecido un sistema electoral que le garantizaba que la oposición triunfante no podría desmantelar el sistema constitucional con los enclaves autoritarios establecidos.

\section{LA REFORM A CONSTITUCIONAL DE 1989: EL TRÁNSITO DE LA CONSTTTUCIÓN OTORGADA A LA CONSTTTUCIÓN PACTADA}

Después de concretarse la derrota del General Pinochet en 1988, se inicia un periodo político distinto que llevará a un proceso de negociación con tensiones, avances y retrocesos, entre el Gobierno Militar, derrotado electoralmente, que debía abandonar el gobierno en marzo de 1990, y la oposición al régimen militar autoritario, estando obligado este último a implementar elecciones presidenciales y parlamentarias competitivas para diciembre de 1989.

El 28 de abril de 1989, el M inistro del Interior, Carlos Cáceres, luego de superar una crisis ministerial, plantea, por encargo del Presidente Pinochet, la proposición de 28 puntos de reforma constitucional, las que simultáneamente envía en Carta a Patricio Aylwin, coordinador de la Concertación de Partidos por la Democracia, solicitando un pronunciamiento a la mayor brevedad posible.

El 2 de mayo de 1989 la Concertación de Partidos por la Democracia en declaración pública rechaza el proyecto de reformas del gobierno por hacer imposible cualquier cambio importante hacia la democracia antes de 1995, en virtud del procedimiento de reforma constitucional que exigía la aprobación de la reforma por dos congresos sucesivos, atando aún más los enclaves autoritarios. Reitera su disposición a la búsqueda de un consenso y reafirma las propuestas hechas en abril de 1989, haciéndose imprescindible la generación íntegra de ambas ramas del Congreso Nacional por votación directa de la ciudadanía y la flexibilización del procedimiento de reforma constitucional para procesar los cambios necesarios para llegar a un régimen democrático.

Luego de diversas escaramuzas políticas y declaraciones de los distintos actores políticos, el viernes 12 de mayo, el Ministro del Interior, don Carlos Cáceres, anuncia la disposición del gobierno a reanudar las conversaciones con los sectores políticos 
para perfeccionar la Constitución Política de la República, la que también había expresado la Concertación de Partidos por la Democracia.

El 16 de mayo se reúnen el M inistro del Interior, don Carlos Cáceres y el vocero de la Concertación de Partidos por la Democracia, don Patricio Aylwin, con el objeto de seguir analizando las eventuales modificaciones a la Constitución, donde se producen acuerd os y divergencias.

El 31 de mayo de 1989 los 17 partidos que integran la Concertación por la Democracia aprueban, con reservas, el proyecto que presentó el gobierno algunos días antes. El Secretario General de la Izquierda Cristiana, Roberto Celedón, expresa el estado de ánimo de las fuerzas opositoras el 31 de mayo en el Diario El M ercurio: "si hay acuerdo ello no significa que la Constitución de 1980 sea integralmente democratizada. No va a ser así. Este acuerdo es el producto de una negociación, porque el objetivo nuestro es ganar un mayor espacio para hacer posible la transición a la democracia".

Se concuerdan así 54 reformas constitucionales, ${ }^{5}$ las que posibilitan buscar las mayorías necesarias en el futuro parlamento para introducir nuevas reformas democratizadoras del sistema constitucional con el objeto de sup rimir los enclaves autoritarios importantes que se mantienen en la Carta Fundamental.

A sí las negociaciones concluyen con reforma constitucional que posibilita el tránsito del autoritarismo militar a un gobierno democrático, con un marco constitucional con fuertes enclaves autoritarios.

El vocero de la Concertación, Patricio Aylwin, afirmaba en la prensa el 2 de junio de 1989, que los partidos opositores al gobierno militar no se sentían coautores de las reformas constitucionales, porque "no nos satisfacen plenamente, pero, a pesar de ello, hemos aceptado concurrir a respaldarlas otorgando nuestro visto bueno, dándoles luz verde...".

El 14 de julio de 1989, la Junta de Gobierno aprueba las reformas al texto constitucional de 1980 y se convoca a plebiscito para el domingo 30 de julio de 1989, para que la ciudadanía se pronuncie aprobando o rechazando las reformas.

Los resultados finales del plebiscito fueron entregados por el Ministerio del Interior el lunes 31 de julio, ellos arrojaron los siguientes resultados:

A probación de las reformas

Rechazo de la reformas

Votos en blanco

Votos nulos
6.056 .440 votos 580.212 votos

114.056 votos

315.918 votos

5 Andrade Gerwitz, Carlos (1991). Reforma de la Constitución Política de la República de Chile. Editorial Jurídica de Chile. Santiago. 
Así, un $85,7 \%$ aprobaba las reformas, un 8,2\% las rechazaba, existiendo entre votos nulos y en blanco un $6 \%$.

Se reinaugura así, a partir de marzo de 1990, un tipo de gobierno presidencialista con una fuerte hegemonia presidencial, con un parlamento debilitado y cuyos contrapesos del ejecutivo se centran más en órganos autónomos como el Tribunal Constitucional, Contraloría General de la República, Banco Central y el rol tutelador del régimen político asignado por la Constitución a las Fuerzas Armadas y al Consejo de Seguridad Nacional. ${ }^{6}$

La eliminación de los enclaves autoritarios requerirá necesariamente, por los altos quórum de reforma constitucional, de amplios consensos entre la Concertación de Partidos por la Democracia y las fuerzas políticas que habían apoyado al régimen autoritario militar, aglutinadas en el partido Unión Democrática Independiente (UDI) y Renovación Nacional (RN).

\section{LA TRANSICIÓN DEL AUTORITARISMO A LA DEM OCRACIA Y LA CONSOLIDACIÓN DEL RÉGIMEN CONSTITUCIONAL DEMOCRÁTICO 1990-2005}

En el periodo se desarrollarán los gobiernos de Patricio Aylwin (1990-1994), de Eduardo Frei Ruiz-Tagle (1994-2000), Ricardo Lagos Escobar (2000-2006). Todos ellos apoyados por la misma coalición política, la Concertación de Partidos por la Democracia, siendo los dos primeros democratacristianos y el tercero socialista con militancia formal en el Partido por la Democracia, el cual será seguido actualmente por el de la Presidenta M ichelle Bachelet Jeria (2006-2010), de militancia socialista.

En el periodo 1990-2005 se concretan en los diversos gobiernos una cantidad significativa de reformas constitucionales, siendo la más trascendente la gran reforma de $2005 .^{7}$

Durante el periodo 1990-1994, se concretaron tres reformas constitucionales, las que posibilitaron los indultos sobre conductas terroristas desarrolladas durante el gobierno militar que buscaron pacificar el país; seguida de la reforma que democratizó los municipios y generó la institucionalidad de los gobiernos regionales, terminando con la reforma que redujo el periodo presidencial de los ocho que consideraba el texto original de la Constitución a seis años.

6 El texto de la Constitución de 1980 modificado en 1989, con sus antecedentes, concordancias, jurisprudencia y bibliografía seleccionada se encuentra publicada por Blanc, N.; NogueiRA, H.; PFefFer, E., y Verdugo, M. (1990). La Constitución Política de la República de Chile. Valparaíso. Ed. Centro de Estudios y A sistencia Legislativa. Universidad Católica de Valparaíso, Chile.

7 Carrasco Delgado, Sergio (2005). "La Constitución Política de la República de Chile y su reforma", en Zúñiga, Francisco (coord.). Reforma Constitucional. Ed. LexisNexis, Santiago, pp. 81-112. 
A ello seguirán las ocho reformas constitucionales del periodo del Presidente Eduardo Frei entre 1994 y 2000, referentes a la creación del M inisterio Público y que viabiliza la reforma procesal penal; la que otorga mayores atribuciones a los municipios; aquella que modifica la composición de la Corte Suprema y posibilita su integración con abogados ajenos a la carrera judicial; la reforma que establece el procedimiento para que la Corte Suprema dé su opinión en materia de leyes orgánicas constitucionales sobre organización y atribución de los tribunales; la reforma que profundiza la igualdad entre hombres y mujeres, modificando el artículo $1^{\circ}$ y $19 \mathrm{~N}^{\circ} 2$ de la Carta Fundamental, eliminando el sesgo de género en el lenguaje del artículo $1^{\circ}$; la reforma que promueve la educación parvularia y que modificó el artículo $10 \mathrm{~N}^{\circ} 2$ de la Constitución y la modificación que redujo los plazos para la segunda votación en la elección presidencial y el periodo de calificación, como asimismo modificó la composición del Tribunal Calificador de Elecciones.

Finalmente se encuentran las cuatro reformas del periodo del Presidente Ricardo Lagos que establece el estatuto constitucional de los ex presidentes de la República; la que modifica la convocatoria y reunión del Congreso Pleno para ratificar reformas constitucionales; la que establece la obligatoriedad y gratuidad de la enseñanza media para las personas que tengan hasta 21 años. Además de la gran reforma que culminó en 2005 y que establece el consenso necesario y básico del estatuto del poder dentro del orden constitucional, lo cual posibilita sostener la efectiva vigencia de un régimen republicano democrático pluralista, con un tipo de presidencialismo puro, con hegemonia presidencial.

La historia y la experiencia constitucional reciente también nos enseña que la Carta Fundamental solo será un orden duradero y estable en la medida que promueva la unidad y la integración de todos los sectores que forman parte de la sociedad política, debiendo reconstruir permanentemente dicha unidad e integración.

La Carta Fundamental tiene que poseer el carácter de un compromiso básico generador y conservador de la unidad, paz y la justicia, posibilitando la expresión de una sociedad plural en sus estructuras e idearios políticos, donde cada uno de los sectores significativos se sienta integrado y tenga un lugar para participar en forma representativa y justa en las decisiones que conciernen al conjunto de la sociedad política.

Las reformas desarrolladas desde 1990 hasta la gran reforma de 2005 buscan concretar estos tres objetivos y funciones de una Constitución, siendo un texto expresión del conjunto de la sociedad y su diversidad, que sea integradora de todos los sectores significativos de la sociedad, posibilitando que todos ellos desarrollen el "sentimiento de Constitución", que sientan la Carta Fundamental suya. Un ámbito importante sobre el cual no se logró consenso fue la modificación del sistema electoral desarrollado por el régimen autoritario militar y resistido por la Concertación de Partidos por la Democracia. 
Dichas reformas han sido el producto de un largo y complejo proceso de negociaciones entre el gobierno y la oposición que se prolongaron desde el inicio mismo de los gobiernos democráticos hasta agosto de 2005.

Los dos proyectos de reforma constitucional que incidían en las denominadas reformas duras y que presentaron parlamentarios de gobierno y oposición, fueron analizados conjuntamente en la Comisión de Constitución, Legislación y Justicia del Senado, generándose un espacio para la búsqueda de acuerdos o consenso de las fuerzas políticas, las que eran monitoreadas desde el gobierno por el Ministro del Interior de la época, don José M iguel Insulza, el cual como Vicepresidente de la República presenta las indicaciones del gobierno mediante Mensaje №221-344, el 10 de septiembre de 2001. Desde entonces hasta 2005 se desarrolló el proceso de búsqueda de consenso.

La reforma de 2005, pone fin a diversos enclaves autoritarios que se mantenían en el texto constitucional, ${ }^{8}$ restablece una clara subordinación de las Fuerzas Armadas al Presidente de la República, el que puede destituir y cambiar a sus comandantes en jefe; se elimina el rol político institucional del Consejo de Seguridad Nacional como parte del poder tutelador del gobierno que había sido concebido en el texto original de la Carta de 1980; ${ }^{9}$ se eliminan los senadores designados y se establece la electividad completa del Senado; ${ }^{10}$ se modifica profundamente la composición del Tribunal Constitucional ${ }^{11}$ y se fortalecen sus competencias; se modifica simplificando el procedimiento de reforma constitucional; ${ }^{12}$ se fortalece constitucionalmente el control parlamentario del gobierno mediante la constitucionalización de comisiones investigadoras e interpelaciones parlamentarias; ${ }^{13}$ se elimina el periodo de sesiones extraordina-

8 Cumplido CereCEDA, Francisco (2005). "Reforma constitucional y régimen político", en Zúñiga, Francisco (coord). Reforma Constitucional. Ed. LexisNexis, Santiago, pp. 113-126.

9 Peña TorRes, Marisol (2005). "Reformas al sistema de remoción de los comandantes en jefe de las Fuerzas Armadas y a la composición y atribuciones del Consejo de Seguridad Nacional", en Nogueira Alcalá, Humberto (Coord.). La Constitución reformada de 2005. Centro de Estudios Constitucionales de Chile. Ed. Librotecnia, Santiago, pp. 507-526. Verdugo M., M ario (2005). "Notas a la reforma constitucional en lo que atañe a las Fuerzas Armadas y Consejo de Seguridad Nacional", en Zúñiga, Francisco (coord). Reforma Constitucional. Ed. LexisNexis, Santiago, pp. 699-710.

10 Pérez LIsicic, Rodrigo (2005)." Senado y reforma constitucional: M odificaciones al artículo 45 de la Constitución de 1980", en Zúñiga, Francisco (coord.). Reforma Constitucional. Ed. LexisNexis, Santiago, pp. 491-506.

11 Colombo C., Juan (2005). "Tribunal Constitucional: integración, competencia y sentencia", en Zúñiga, Francisco (coord.). Reforma Constitucional. Ed. LexisNexis, Santiago, pp. 551-592. Ríos Álvarez, Lautaro. El nuevo Tribunal Constitucional. En Zúñiga, Francisco (coord). Reforma Constitucional. Ed. LexisNexis, Santiago, 2005.

12 ZúNIGA URBina, Francisco (2005). “Reforma del capítulo XV: 'Reforma de la Constitución'”, en Zúñiga, Francisco (coord.). Reforma Constitucional. Ed. LexisNexis, Santiago, pp. 761-770. BuLnes Aldunate, Luz (2005). "La reforma constitucional al Congreso Nacional", en Nogueira Alcalá, Humberto (Coord.). La Constitución reformada de 2005. Centro de Estudios Constitucionales de Chile. Ed. Librotecnia, Santiago, pp. 251-273.

13 CoRDERO Q., Eduardo (2005). "La facultad fiscalizadora de la Cámara de Diputados”, en Zúñiga, Francisco (coord.). Reforma Constitucional. Ed. LexisNexis, Santiago, pp. 507-526. ZúNIIGA URBINA, Francisco y VeGa M ÉndeZ, Francisco (2005). “Control político de la Cámara de diputados en la reforma constitucional", en Nogueira Alcalá, Humberto (Coord.). La Constitución reformada de 2005. Centro de Estudios Constitucionales de Chile. Ed. Librotecnia, Santiago. 
rio del Congreso y el derecho preferente del Presidente para convocarlo y determinar los proyectos a discutir en el mismo; se elimina la facultad presidencial de calificar las urgencias en los proyectos de ley; se perfecciona el sistema de integración del derecho convencional internacional al derecho interno y se clarifica su aplicabilidad mientras no sea retirado de acuerdo con las normas del derecho internacional, sin perjuicio de fortalecer el rol del parlamento en la información acerca de la conclusión de tratados y las condiciones de su aprobación; ${ }^{14}$ se desarrollan modificaciones a los estados de excepción constitucional disminuyendo los derechos que pueden ser afectados en algunos de ellos y determinando el control parlamentario en reemplazo del Consejo de Seguridad Nacional; ${ }^{15}$ se elimina del texto constitucional el sistema electoral parlamentario binominal, aunque se mantiene en un régimen de ley orgánica constitucional con quórum de reforma ordinaria de la Constitución (tres quintos de los diputados y senadores en ejercicio); se modifica el sistema de reemplazo de parlamentarios en caso de vacancia del cargo, entre otros aspectos menos trascendentes.

\subsection{Los derechos fundamentales y sus garantías en la Constitución vigente}

Estos derechos no son sólo los enumerados en el texto del artículo $19^{\circ}$ de la Constitución Política, ya que la Carta Fundamental asegura cualquier otro derecho esencial que emane de la naturaleza humana, según establece el artículo $5^{\circ}$, teniendo el deber los órganos estatales de respetarlos y promoverlos, siendo tales derechos limites al ejercicio de la soberanía, tanto los asegurados por la Constitución como también los derechos asegurados por los tratados internacionales ratificados por Chile y que se encuentren vigentes, de acuerdo con la reforma constitucional de 1989.

En general, podemos señalar que éste es uno de los capítulos de la Constitución más logrado, especialmente respecto de los derechos individuales, aun cuando con ciertas imperfecciones en materia de derechos sociales y económicos, producto de la concepción del constituyente autoritario de 1980, lo que se corrige en parte con la reforma de 1989, al establecer el deber del Estado de respetar y promover los derechos establecidos por los tratados internacionales ratificados por Chile y que se en-

14 Nogueira Alcalá, Humberto (2005). "A spectos fundamentales de la reforma constitucional de 2005 en materia de tratados internacionales", en Nogueira A Icalá, Humberto (Coord.). La Constitución reformada de 2005. Centro de Estudios Constitucionales de Chile. Ed. Librotecnia, Santiago, pp. 381-404. Llanos Mansilla, Hugo (2005). "Los tratados y la reforma constitucional”, en Nogueira Alcalá, Humberto (Coord.). La Constitución reformada de 2005. Centro de Estudios Constitucionales de Chile. Ed. Librotecnia, Santiago, pp. 345-380.

15 Rios Álvarez, Lautaro (2005). “Los estados de excepción constitucionales en una perspectiva humanista", en Nogueira Alcalá, Humberto (Coord.). La Constitución reformada de 2005. Centro de Estudios Constitucionales de Chile. Ed. Librotecnia, Santiago, pp. 319-344. Bulnes Aldunate, Luz (2005). “Los estados de excepción frente a la reforma constitucional", en Francisco (coord.). Reforma Constitucional. Ed. LexisNexis, Santiago, pp. 417-487. Saenger Gianoni, Fernando y Jiménez Loosli, Fernando (2005). "Los Estados de excepción constitucional", en Zúñiga, Francisco (coord.). Reforma Constitucional. Ed. LexisNexis, Santiago, pp. 437-450. Nogueira AlcalÁ, Humberto. Derechos fundamentales y garantías constitucionales. Tomo I. Ed. Librotecnia, 2007, pp. 121-194. 
cuentran vigentes, encontrándose en tal situación, entre otros, el Pacto Internacional de Derechos Sociales, Económicos y Culturales de Naciones Unidas, los que forman parte del bloque constitucional de derechos.

La Carta de 1980 no establece en ninguna de sus disposiciones el derecho a un nivel de vida digno o adecuado como un derecho de las personas, sólo en el artículo 10 , inciso $4^{\circ}$ determina que el Estado debe contribuir a crear condiciones para la realización material y espiritual de la persona, como asimismo el inciso final del artículo $1^{\circ}$ establece el deber del Estado de promover la integración armónica de todos los sectores sociales y asegurar el derecho de las personas a participar con igualdad de oportunidades en la vida nacional.

El numeral 16 del artículo 19 reconoce la libre elección del trabajo con una justa retribución. A simismo, la disposición citada menciona el derecho a la negociación colectiva con la empresa en que laboran los trabajadores, y la huelga se menciona sólo para establecer que no podrán declararse en huelga los funcionarios del Estado ni de las M unicipalidades, ni las personas que trabajan en corporaciones o empresas que atienden servicios de utilidad pública o cuya paralización cause un grave daño a la salud, a la economía del país, al abastecimiento de la población o a la seguridad nacional.

El derecho a la sindicación se asegura en los casos y en la forma que la ley señala, la afiliación sindical será siempre voluntaria (art. 19, № 19), estas organizaciones sindicales adquieren personalidad jurídica por el solo registro de sus estatutos en las formas que señala la ley.

El derecho a la protección de la salud está asegurado constitucionalmente en el artículo 19, № 9. El Estado protege el libre e igualitario acceso a las acciones de promoción, protección y rehabilitación del individuo. Es deber preferente del Estado garantizar la ejecución de las acciones de salud, sea que se presten a través de instituciones públicas o privadas. Cada persona tiene el derecho a elegir el sistema de salud al que debe acogerse, sea este estatal o privado.

La Constitución asegura el derecho a la seguridad social, estando la acción del Estado dirigida a garantizar a todos los habitantes el goce de prestaciones básicas uniformes, sea que se otorguen a través de instituciones públicas o privadas. Sin embargo, en la práctica, el Decreto ley 3.500 que regula la materia, permite que la persona se integre al sistema solo si ejerce una actividad mediante la cual genere ingresos. El Estado excepcionalmente se obliga a enterar aportes en caso de que la pensión devengada llegare a ser inferior a la pensión mínima.

El artículo 19, № 8 de la Carta Fundamental asegura el derecho a vivir en un medio ambiente libre de contaminación, constituyendo un deber del Estado velar porque este derecho no sea afectado y tutelar la preservación de la naturaleza. La ley puede establecer restricciones a ciertas libertades y derechos para proteger el medio ambiente. 
Entre los derechos culturales se consagra el derecho a la educación en el artículo 19, № 10. Se asegura el derecho y deber preferente de los padres de educar a sus hijos. La educación básica y media es obligatoria, debiendo el Estado financiar un sistema gratuito con tal objeto, destinado a asegurar el acceso a ella de toda la población. El mismo artículo 19 № 10 establece que corresponderá al Estado fomentar el desarrollo de la educación en todos sus niveles; estimular la investigación científica y tecnológica, la creación artística y la protección e incrementar del patrimonio cultural de la Nación.

La concepción neoliberal del constituyente en materia económica se establece debilitando el rol del Estado en materias económico-sociales, limitando al Estado en materia de actividades empresariales, las que puede desarrollar sólo habilitado por una ley de quórum calificado para cada caso específico; se asegura la libre iniciativa económica y empresarial (art. $19 \mathrm{~N}^{\circ} 21$ ); se determina la obligación de igualdad de trato que debe dar el Estado en materia económica (art. $19 \mathrm{~N}^{\circ} 22$ ) y se fortalece el derecho de propiedad privada en relación a la Carta de 1925, aunque se admiten limitaciones a la propiedad producto de su función social (artículo 19 no 24).

Se consagra la garantía normativa del respeto al contenido esencial de los derechos asegurado en el artículo 19, № 26, consistente en "la seguridad de que los preceptos legales que por mandato de la Constitución regulen o complementen las garantías que establece o que las limiten en los casos que ella autoriza, no podrán afectar los derechos en su esencia, ni imponer condiciones, tributos o requisitos que impidan su libre ejercicio".

A simismo se establecen las acciones constitucionales de amparo o habeas corpus y el recurso de protección (similar al amparo o tutela en el derecho comparado latinoamericano). Este último no asegura todos los derechos constitucionales y humanos, sino especialmente los derechos civiles o individuales, quedando sin este recurso diversos derechos sociales y prestacionales, lo que vulnera el artículo 25 de la Convención Americana sobre Derechos Humanos.

\subsubsection{Derechos políticos}

La Constitución señala que son ciudadanos los chilenos que hayan cumplido dieciocho años de edad y que no hayan sido condenados a pena aflictiva. La calidad de ciudadano otorga los derechos de sufragio y de optar a cargos de elección popular (arts. 13, 25, 48 y 50), como asimismo, el derecho a organizar partidos políticos (art. 19, № 15), materia regulada por una ley orgánica constitucional de Partidos Políticos № 18.603 publicada en el "Diario Oficial" № 32.729, el 23 de marzo de 1987, que requiere de los cuatro séptimos de los diputados y senadores en ejercicio para su aprobación, modificación o derogación, disposiciones constitucionales y legales elaboradas con una motivación anti partidos que sostenía el régimen militar, generando así un conjunto de restricciones y limitaciones, que hasta el término del periodo analizado aún no habían podido ser superadas. Finalmente, los ciudadanos tienen derecho de participar en la aprobación o rechazo de reformas constitucionales bajo los 
supuestos de los artículos 128 y 129 de la Carta Fundamental; en el artículo 118 de la Carta Fundamental se establece, con la reforma de 1989, el derecho de los electores municipales a resolver en consulta no vinculante o en plebiscito las materias de administración local que le sean sometidas por el Alcalde con acuerdo del Concejo M unicipal o a iniciativa de $2 / 3$ de los concejales, o de iniciativa ciudadana conforme a los requisitos establecidos en la LOC de Municipalidades.

\subsection{Los partidos políticos y el sistema electoral}

\section{3..2.1. El sistema de partidos políticos}

El sistema de partidos políticos chilenos tienen su fundamento, origen y desarrollo en el siglo XX en los cleavages sociales desarrollados historicamente como lo sostienen Seymour Martin Lipset y Stein Rokkan y que se explicitaba en el sistema de partidos, el Conservador de raiz católica con defensa de intereses agrarios representados; el Partido Liberal de una derecha con defensa de intereses económicos urbanos, del mundo industrial y de servicios; derecha que se refundirá después de su desastre electoral de 1965, en el Partido Nacional; el Partido Comunista, de raiz marxista leninista, con apoyo de sector de trabajadores de la actividad minera, industrial y sectores intelectuales; el desarrollo de un partido radical librepensador y con perspectiva progresista que aglutina a sectores medios; un partido demócrata cristiano, que se desarrolla en quiebre con el catolicismo conservador en una perspectiva de un cristianismo progresista afianzado en sectores medios y con penetración en sectores campesinos, trabajad ores y poblacionales que desplaza al radicalismo del centro del espectro político; los socialistas que con diversos matices participan de la construcción de un socialismo con fuertes rasgos estatistas y cuya base es esencialmente poblacional y de trabajadores industriales y algunos sectores medios.

Como bien señala Valenzuela, los partidos resurgieron en el último periodo del régimen autoritario con una realidad similar al sistema partidario previo a 1973, siguiendo las líneas de conflicto presentes hasta ese instante. ${ }^{16}$ El régimen autoritario fracasó en su búsqueda de cambiar el sistema de partidos a través del régimen autoritario militar y sus transformaciones sociales y la ayuda de la ingeniería electoral del sistema electoral diseñado en el último año del régimen autoritario, después de la derrota plebiscitaria del General Pinochet de 1988.

16 Valenzuela, Samuel. "Orígenes y Transformación del Sistema de Partidos en Chile", en Revista Estudios Públicos N² 58 , otoño de 1995, pp. 6-13. Ver asimismo, Scully, Timothy y VAlenzuela, Samuel. "De la Democracia a la Democracia. Continuidad y Variaciones en las Preferencias del Electorado y en el Sistema de Partidos en Chile", en Revista Estudios Públicos, N 51, Invierno 1993. A simismo, NoguelRA A., Humberto (1992). "Introducción a los Sistemas Electorales y al Sistema Electoral Chileno". Serie Documentos de Estudios N 3. Corporación Participa. Santiago de Chile. Noguelra, Humberto (1993). Regímenes Políticos Contemporáneos. Editorial Jurídica de Chile. Santiago. SIAVELIS, Peter. Continuity and change in the chilean party system. Comparative Political Studies 30, 6 December, pp. 651-674. 
El resurgimiento del sistema de partidos se realiza en base a dos partidos de derecha, la Unión Democrática Independiente (UDI), que fue el sostén civil esencial del régimen autoritario militar y defensor de una democracia protegida y de pluralismo limitado, defensor de una plena autonomía de cuerpos intermedios, hasta los últimos años del siglo XX; paulatinamente se produce una cierta desvinculación y toma de distancia del régimen autoritario militar en la primera década del siglo XXI, con una estructura política elitista pero con significativo trabajo y apoyo en la base social; y Renovación Nacional integrada por los sectores tradicionales de la derecha política anterior al régimen militar, con una concepción moderna neoliberal y una mayor dosis de compromiso democrático pluralista; ambos sectores actuarán en pacto constituyendo la oposición de derecha, hoy denominada Alianza por Chile, y la coalición de gobierno la Concertación de Partidos por la Democracia.

La evolución electoral durante el periodo 1989-2000 de estas dos fuerzas de derecha es el siguiente:

\begin{tabular}{|l|r|r|r|r|r|r|r|r|c|}
\hline & $\begin{array}{r}\text { Dip. } \\
\mathbf{1 9 8 9}\end{array}$ & $\begin{array}{r}\text { Senad. } \\
\mathbf{1 9 8 9}\end{array}$ & $\begin{array}{r}\text { Munic. } \\
\mathbf{1 9 9 2}\end{array}$ & $\begin{array}{r}\text { Dip. } \\
\mathbf{1 9 9 3}\end{array}$ & $\begin{array}{r}\text { 1993. } \\
\mathbf{1 9 9 3}\end{array}$ & $\begin{array}{r}\text { Munic. } \\
\mathbf{1 9 9 6}\end{array}$ & $\begin{array}{r}\text { Dip. } \\
\mathbf{1 9 9 7}\end{array}$ & $\begin{array}{r}\text { Senad. } \\
\mathbf{1 9 9 7}\end{array}$ & $\begin{array}{r}\text { Munic. } \\
\mathbf{2 0 0 0}\end{array}$ \\
\hline RN & 19,5 & 21,1 & 15,7 & 17,5 & 14,9 & 18,5 & 17,6 & 15,4 & 18,5 \\
\hline UDI & 14,5 & 13,0 & 13,4 & 15,0 & 13,7 & 13,0 & 17,2 & 21,2 & 21,1 \\
\hline
\end{tabular}

Fuente: Servicio Electoral.

En la Concertación de Partidos por la Democracia se reunirán las fuerzas políticas que buscan restablecer el régimen constitucional con una democracia plena y pluralista, con una perspectiva de Estado Social y Democrático de Derecho, buscando un desarrollo político, social y económico con mayor integración de los diversos sectores y con mayor igualación de oportunidades, además de afianzar niveles adecuados de goce y ejercicio de derechos económicos y sociales. A quí se encuentran la Democracia Cristiana, los diversos sectores socialistas reunificados en el Partido Socialista, el Partido Radical Social Demócrata y el Partido Por la Democracia, que constituyen la columna vertebral de este pacto.

Elecciones de Diputados 1989- 2005:

\begin{tabular}{|lccccc|}
\hline Partidos & $\mathbf{1 9 8 9}$ & $\mathbf{1 9 9 3}$ & $\mathbf{1 9 9 7}$ & $\mathbf{2 0 0 1}$ & $\mathbf{2 0 0 5}$ \\
\hline Partido Demócrata Cristiano & $24,67 \%$ & $24,74 \%$ & $18,90 \%$ & $16,52 \%$ & $19,02 \%$ \\
\hline Partido por la Democracia & $10,87 \%$ & $10,81 \%$ & $10,32 \%$ & $11,12 \%$ & $14,12 \%$ \\
\hline Partido Socialista & & $10,88 \%$ & $9,09 \%$ & $8,73 \%$ & $9,21 \%$ \\
\hline Partido Radical Social Demócrata & & $2,58 \%$ & $3,54 \%$ & $3,24 \%$ \\
\hline
\end{tabular}


Junto a ellos se unirán pequeños movimientos politicos como son el MAPU, la Izquierda Cristiana, los Humanistas y los Ecologistas, movimientos estos últimos que se alejarán de la Concertación y se unirán luego en coalición con el Partido Comunista que mantiene su raigambre marxista leninista y que constituye la fuerza extraparlamentaria opositora de izquierda que se presenta en las elecciones de 2005 como el Pacto Juntos Podemos Más que obtiene un 7,4\% de los votos.

Elecciones de Diputados 1993-2005:

\begin{tabular}{|lrrrr|}
\hline Años & $\mathbf{1 9 9 3}$ & $\mathbf{1 9 9 7}$ & $\mathbf{2 0 0 1}$ & $\mathbf{2 0 0 5}$ \\
\hline Partido Comunista & $4,55 \%$ & $5,66 \%$ & $4,56 \%$ & $4,71 \%$ \\
\hline
\end{tabular}

Sin lugar a dudas el nuevo quiebre en el dilema recuperación democracia-fuerzas que respaldan al autoritarismo, marca fuertemente las nuevas coaliciones políticas hasta el fin del periodo analizado. Por otra parte, a diferencia de la etapa pre autoritaria, las fuerzas políticas no desarrollan proyectos ideológicos polarizad os y excluyentes, sino con tendencia centrípeta, con niveles poco diferenciados en el ámbito programático, a excepción del Partido Comunista.

Presentamos el cuadro con las tres últimas elecciones parlamentarias del periodo 1997-2005

Elecciones generales de Diputados, año 1997:

\begin{tabular}{|l|r|r|r|r|}
\hline & VOTOS & PORCENTAJE & CANDIDATOS & ELECTOS \\
\hline A.- Humanista & 168.597 & $2,91 \%$ & 90 & - \\
\hline B.- Unión Por Chile & 2.101 .392 & $36,26 \%$ & 119 & 47 \\
\hline $\begin{array}{l}\text { C.- Concertación de } \\
\text { Partidos por la Democracia }\end{array}$ & 2.927 .692 & $50,51 \%$ & 120 & 69 \\
\hline D.- La Izquierda & 434.148 & $7,49 \%$ & 86 & - \\
\hline E.- Chile 2000 & 123.922 & $2,14 \%$ & 25 & 2 \\
\hline Independientes (Fuera de Pacto) & 40.022 & $0,69 \%$ & 2 & 2 \\
\hline Válidamente Emitidos & $\mathbf{5 . 7 9 5 . 7 7 3}$ & & $\mathbf{4 4 2}$ & $\mathbf{1 2 0}$ \\
\hline
\end{tabular}


Elecciones generales de Diputados, año 2001:

\begin{tabular}{|l|r|r|r|r|}
\hline LISTA/PACTO & VOTOS & PORCENTAJE & CANDIDATOS & ELECTOS \\
\hline A.- Partido Comunista & 320.688 & $5,22 \%$ & 80 & - \\
\hline B.- Partido Humanista & 69.692 & $1,13 \%$ & 42 & - \\
\hline C.- Alianza por Chile & 2.720 .195 & $44,27 \%$ & 119 & 57 \\
\hline D.- Partido Liberal & 3.475 & $0,06 \%$ & 4 & - \\
\hline $\begin{array}{l}\text { E.- Concertación de } \\
\text { Partidos por la Democracia }\end{array}$ & 2.942 .989 & $47,90 \%$ & 120 & 62 \\
\hline Independientes (Fuera de Pacto) & 86.964 & $1,42 \%$ & 16 & 1 \\
\hline Válidamente Emitidos & $\mathbf{6 . 1 4 4 . 0 0 3}$ & & $\mathbf{3 8 1}$ & $\mathbf{1 2 0}$ \\
\hline
\end{tabular}

Elecciones Generales de Diputados 2005:

\begin{tabular}{|l|r|r|r|r|}
\hline LISTA/PACTO & VOTOS & PORCENTAJE & CANDIDATOS & ELECTOS \\
\hline $\begin{array}{l}\text { A.- Fuerza Regional } \\
\text { Independiente }\end{array}$ & 77.213 & $1,17 \%$ & 23 & 1 \\
\hline B.- Concertación Democrática & 3.417 .207 & $51,76 \%$ & 120 & 65 \\
\hline C.- Juntos Podemos Más & 488.618 & $7,40 \%$ & 115 & - \\
\hline D.- Alianza & 2.556 .386 & $38,72 \%$ & 120 & 54 \\
\hline Independientes (Fuera de Pacto) & 62.387 & $0,94 \%$ & 8 & - \\
\hline Válidamente Emitidos & $\mathbf{6 . 6 0 1 . 8 1 1}$ & & $\mathbf{3 8 6}$ & $\mathbf{1 2 0}$ \\
\hline
\end{tabular}

Fuente: Ministerio del Interior y Servicio Electoral, Chile.

3.2.2. El sistema electoral parlamentario.

El sistema electoral parlamentario actual tiene sus coordenadas básicas en el texto de la Constitución Política de 1980, las cuales complementadas específicamente por la 
Ley Orgánica Constitucional № 18.556 sobre Sistema de Inscripciones Electorales y Servicio Electoral, y por la Ley Orgánica Constitucional № 18.700 sobre Votaciones Populares y Escrutinios que estableció el sistema electoral aplicable a las elecciones de senadores y diputados (arts. 109 bis, 178, 179, 180 y 181) estableciendo un sistema electoral binominal "sui generis" que no es mayoritario ni proporcional.

La Ley Orgánica Constitucional № 18.700 sobre Votaciones Populares y Escrutinios en su articulo 109ㅇ bis da a conocer el sistema de selección de los candidatos al Congreso Nacional, sea la Cámara de diputados o el Senado.

Una misma lista tendrá los dos cargos en disputa en cada distrito o circunscripción si tiene más del doble de votos que la segunda lista que le sigue en votación. Si esta hipótesis no se da, cada una de las dos listas más votadas obtendrá la elección de un cargo, el que corresponderá dentro de cada lista al candidato que haya obtenido más votos preferenciales. Si el segundo cargo que debe ser llenado se lo disputan dos o más listas o nóminas con igual votación, se proclama electo al candidato que haya obtenido mayor número de preferencias individuales. En el caso que dos listas estén empatadas y dentro ellas el candidato de cada lista tiene la misma votación, el Tribunal Calificador de Elecciones, en audiencia pública, debe efectuar entre ellos un sorteo y proclamará electo al que salga favorecido. Lo mismo ocurre en el caso que empaten en votos preferenciales los dos candidatos de una lista a la que sólo le corresponde un cargo.

Este sistema binominal sui generis, ${ }^{17}$ por regla general fortalece la segunda fuerza electoral en desmedro de la primera, las cuales por regla general obtienen el mismo número de parlamentarios en cada distrito, ya que basta que la segunda lista tenga al menos la mitad de los votos de la primera lista para obtener uno de los dos parlamentarios en disputa en cada distrito o circunscripción, siendo excepcional el caso en que la primera lista obtiene más del doble de votos que la segunda lista en competencia.

El sistema impide la representación de las demás fuerzas políticas que no pertenecen a los dos bloques o pactos más importantes, lo que implica que estas fuerzas se expresan extraparlamentariamente. Ello hace que los partidos se aglutinen en dos pactos electorales con pluralidad de fuerzas políticas, la A lianza por Chile (derecha) y la Concertación de Partidos por la Democracia. El Partido Comunista u otra fuerza política en este esquema no tiene posibilidades de obtener parlamentarios salvo que tenga mayoría en un distrito o circunscripción específico, lo que no ha ocurrido en todo el periodo analizado.

17 PAstor, Daniel (2004). "Origins of the Chilean Binominal Election System", Revista de Ciencia Política Vol. XXIV N 1. FERnÁndeZ, M ario (2000). "El Sistema Electoral Chileno. Dilucidando Equívocos y A daptando Fórmulas", en A gustín Squella y Osvaldo Sunkel (eds.), Democratizar la Democracia. Reformas Pendientes, Ed. LOM, Santiago, pp. 105-119. CAREY, John M. y Siavelis, Peter (2003). "El seguro para los subcampeones electorales y la sobrevivencia de la Concertación", Estudios Públicos 90 (Otoño), pp. 5-27. 
Es un sistema que tiende a la bipolarización en dos alianzas electorales fuertes. ${ }^{18}$ Una de sus fortalezas son los incentivos a la gobernabilidad, ya que la elección presidencial marca las alianzas en las elecciones parlamentarias, donde los partidos se unen en pos de la posibilidad de acceder al gobierno. Los estímulos para la formación de coaliciones han aumentado en comparación al Chile pre-autoritario. Es innegable que la Alianza por Chile (derecha) y la Concertación (centro izquierda) son las coaliciones más largas y perdurables de la historia contemporánea chilena.

Una de sus debilidades consiste en que tiene poca representatividad para lograr la distribución de escaños en el Congreso, en la medida que impide la obtención de mandatos por las terceras y siguientes fuerzas políticas.

La ausencia de competencia entre las listas debilita el significado y la relevancia del voto de los ciudadanos. A su vez, se ha llegado incluso a que una coalición lleve un solo candidato, con lo cual está prácticamente elegido antes que los ciudadanos voten en la elección.

Los líderes de los partidos están forzados a comprometerse en elaboradas y agotadoras negociaciones para reunir listas de dos candidatos en los 60 distritos electorales del país. Los partidos fuertes deben considerar necesariamente las demandas de los partidos pequeños, porque sus votos son necesarios en las elecciones presidenciales, contribuyen en algunos casos a posibilitar la existencia de doblajes en algunos distritos y permiten mantener la coalición. Las negociaciones entre los partidos implica en algunos casos ceder algunos asientos en la Cámara de Diputados a cambio de candidaturas senatoriales o viceversa. Los partidos fuertes de los subpactos de la concertación usan asimismo las encuestas de opinión pública y los resultados previos para dividir equitativamente las candidaturas a lo largo del país.

A su vez, los partidos conocen su porcentaje de votación aproximadamente, por lo que las directivas partidarias negocian intra coalisión o pacto, las candidaturas, llevando candidatos fuertes que serán elegidos y candidatos débiles que sirven solo de acompañamiento, lo que hace que el ciudadano sólo decide la orientación general por la que desea votar pero no tiene ninguna influencia en quiénes son los candidatos que se elegirán, los que ya están predeterminados, todo lo cual desincentiva la participación ciudadana en las elecciones.

Los pactos electorales en este periodo analizado están divididos en dos «sub-pactos», que comparten alguna afinidad ideológica o programática, y forman otra unidad negociadora. La Concertación de Partidos por la Democracia, comprende un sub-pacto de la izquierda (el Partido por la Democracia, PPD; el Partido Socialista, PS; el Parti-

18 NAVIA, Patricio y CABEZAS, José M iguel (2005). “Efecto del sistema binominal en el número de candidatos y de partidos en elecciones legislativas en Chile, 1989-2001", Revista Política. Vol. 45 (primavera), pp. 29-52. Guzmán, Eugenio (1993). "Reflexiones sobre el sistema binominal", Revista Estudios Públicos 51 (invierno), pp. 303-324. 
do Radical, PR) y el otro sub-pacto está constituido por la Democracia Cristiana, así como independientes asociados con cada sub-pacto. La Alianza por Chile está compuesta por los dos partidos de derecha más importantes (Renovación Nacional, RN; y la Unión Demócrata Independiente, UDI), cada uno constituye un sub-pacto dentro de su propio pacto. Estos dos sub-pactos están asociados en ocasiones a pequeños partidos y candidatos independientes

Distribución de Diputados entre partidos políticos en 2005:

\begin{tabular}{|l|r|r|r|r|}
\hline \multicolumn{1}{|l|}{ Lista } & \multicolumn{1}{|c|}{$\begin{array}{c}\text { Número } \\
\text { de votos }\end{array}$} & Porcentaje & Candidatos & Diputados \\
\hline $\begin{array}{l}\text { A. Fuerza Regional } \\
\text { Independiente }\end{array}$ & 77.213 & $1,17 \%$ & 23 & 1 \\
$\begin{array}{l}\text { Alianza Nacional de } \\
\text { los Independientes }\end{array}$ & 20.191 & $0,31 \%$ & 7 & 0 \\
$\begin{array}{l}\text { Partido de Acción } \\
\text { Regionalista }\end{array}$ & 26.698 & $0,40 \%$ & 3 & 1 \\
Independientes Lista A & 30.324 & $0,46 \%$ & 13 & 0 \\
\hline B. Concertación Democrática & 3.417 .207 & $51,76 \%$ & 120 & 65 \\
Partido Demócrata Cristiano & 1.370 .501 & $20,76 \%$ & 56 & 20 \\
Partido por la Democracia & 1.017 .956 & $15,42 \%$ & 27 & 21 \\
Partido Socialista & 663.561 & $10,05 \%$ & 21 & 15 \\
Partido Radical Social & 233.564 & $3,54 \%$ & 9 & 7 \\
Demócrata & 131.625 & $1,99 \%$ & 7 & 2 \\
Independientes Lista B & 488.618 & $7,40 \%$ & 115 & 0 \\
\hline C. Juntos Podemos Más & 339.547 & $5,14 \%$ & 62 & 0 \\
Partido Comunista & 102.842 & $1,56 \%$ & 33 & 0 \\
Partido Humanista & 46.229 & $0,70 \%$ & 20 & 0 \\
Independientes Lista C & & & \\
\hline
\end{tabular}




\begin{tabular}{|c|c|c|c|c|}
\hline D. Alianza & 2.556 .386 & $38,73 \%$ & 120 & 54 \\
\hline Renovación Nacional & 932.422 & $14,12 \%$ & 50 & 19 \\
\hline $\begin{array}{l}\text { Unión Demócrata } \\
\text { Independiente }\end{array}$ & 1.475 .901 & $22,36 \%$ & 59 & 33 \\
\hline Independientes Lista D & 148.063 & $2,24 \%$ & 11 & 2 \\
\hline $\begin{array}{l}\text { Z. Independientes } \\
\text { (Fuera de Pacto) }\end{array}$ & 62.387 & $0,95 \%$ & 8 & 0 \\
\hline Válidamente emitidos & 6.601 .389 & $91,59 \%$ & & \\
\hline Blancos & 218.600 & $3,03 \%$ & & \\
\hline Nulos & 383.940 & $5,33 \%$ & & \\
\hline Total & 7.207.351 & $100,00 \%$ & 386 & 120 \\
\hline Total de electores habilitados & 8.220 .897 & & & \\
\hline
\end{tabular}

Fuente: Tribunal Calificador de Elecciones de Chile.

\subsection{La defensa de la Constitución y jurisdicción constitucional}

El desarrollo de la jurisdicción constitucional en Chile ha sido un proceso lento, no ausente de obstáculos y con poco apoyo de los Tribunales Ordinarios de Justicia.

El Tribunal Constitucional fue incorporado al ordenamiento jurídico en la reforma constitucional de 23 de enero de 1970 a la Constitución de 1925, rigiendo desde 1971 hasta el Golpe de Estado del 11 de septiembre de 1973, aun cuando formalmente fue disuelto en noviembre de 1973 por Decreto Ley 119 del 10 de octubre de dicho año. Durante el breve lapso que el Tribunal Constitucional operó su jurisprudencia fue bien recibida, salvo una sola excepción, existiendo consenso de los buenos servicios rendidos por el Tribunal a la República, como asimismo su corta vida permitió valorar la necesidad de ampliar sus competencias para hacer efectivo en plenitud el Estado de Derecho y el principio de supremacía constitucional.

La Carta de 1980 mantiene un control represivo de constitucionalidad de los preceptos legales en forma concentrada y con efectos inter partes en la Corte Suprema de Justicia, a través del denominado "recurso de inaplicabilidad por inconstitucionalidad", establecido en el artículo 80 de la Carta Fundamental. Dicho control de constitucionalidad de los preceptos legales solo declara inaplicable un precepto legal en una 
gestión judicial concreta, ya no juicio como decía la Carta de $1925,{ }^{19}$ no dejando duda alguna de que puede declararse inaplicable un precepto de rango legal en una gestión judicial no contenciosa.

El precepto legal considerado contrario al enunciado normativo constitucional, suspende su eficacia para ese caso particular, sin invalidarlo, ya que dicho precepto normativo considerado inconstitucional en dicha gestión judicial continúa formando parte del ordenamiento jurídico. A ello debe agregarse que la sentencia de la Corte Suprema que determina la inaplicabilidad del precepto legal no tiene fuerza obligatoria ni efectos persuasivos respecto de los tribunales inferiores: tribunales de primera instancia y Cortes de A pelaciones. Todo ello muestra que este control represivo, concreto y con efectos inter partes, constituye una institución jurídica débil como instrumento para dotar de fuerza normativa a la Constitución y dar protección efectiva a los derechos esenciales de las personas.

Este sistema de control concentrado de constitucionalidad de carácter represivo en manos de la Corte Suprema, ${ }^{20}$ procedía a iniciativa de la parte afectada en la gestión judicial, ya sea que la gestión se encontraba en otra instancia de los tribunales ordinarios o ante la propia Corte Suprema, como asimismo, procedía también de oficio $^{21}$ cuando el asunto estaba radicado en la propia Corte Suprema, lo que constituyó una innovación de la Carta de 1980.

La Constitución de 1980 restableció el Tribunal Constitucional, el cual tiene en un capítulo propio, cuyos artículos 81 a 83 regulaban su integración y competencias, ${ }^{22}$

19 El artículo 86 de la Constitución de 1925 disponía: “La Corte Suprema, en los casos particulares de que conozca o le fueren sometidos en recurso interpuesto en juicio que se siguiere ante otro Tribunal, podrá declarar inaplicable, para ese caso, cualquier precepto legal contrario a la Constitución. Este recurso podrá deducirse en cualquier estado del juicio, sin que se suspenda su tramitación".

20 Ver Rios A., Lautaro (2002). "El control difuso de constitucionalidad de la ley en la República de Chile", en Revista lus et Praxis, año 8 № 1, Ed. Universidad de Talca, Chile, pp. 389-418.

21 La Corte Suprema ha ejercido en algunas ocasiones este control de oficio, siendo la última oportunidad que lo ha ejercido con motivo de la delegación de facultades jurisdiccionales en materia tributaria, fallo del 20 de diciembre de 2002.

22 Sobre la materia puede consultarse AndRAde Gerwitz, Carlos (1996). "Tribunal Constitucional", en Cuadernos de A nálisis Jurídico № 31, Ed. Facultad de Derecho, Universidad Diego Portales, Santiago, Chile. Bertelsen, Raúl y otros (1987). "Función del Tribunal Constitucional de 1980", en Estudios Públicos № 27, Santiago, Chile. Cum PLIdo CereCedA, Francisco (1989). "Tribunal Constitucional y control ideológico", en La Revista de Derecho № 1, Ed. Facultad de Derecho, Universidad Central de Chile. Nogueira AlCALÁ, Humberto (1991). "El Tribunal Constitucional chileno", en Lecturas Constitucionales Andinas № 1, Ed. Comisión Andina de Juristas, Lima, Perú. Rios Álvarez, Lautaro (1988). “La Justicia Constitucional en Chile", en La Revista de Derecho № 1, Ed. Facultad de Derecho, Universidad Central, Santiago, Chile. RIVERA, Teodoro (1984). "El Tribunal Constitucional", en Revista Chilena de Derecho, Volumen 11 № 23, Santiago, Chile. Rivera, Teodoro (1986). “Función y composición del Tribunal Constitucional de 1980", Documento de Trabajo № 74, Centro de Estudios Públicos, Santiago, Chile. Siıva Bascuñán, A lejandro y Silva Gallinato, M aría Pía (1993). "La misión del Tribunal Constitucional", en XXIV Jornadas de Derecho Público, Revista Chilena de Derecho, Ed. Facultad de Derecho, Pontificia Universidad Católica de Chile, Santiago, Chile. ZúñIGA URBina, Francisco (2002). Elementos de jurisdicción constitucional, Tomo II, Ed. Universidad Central de Chile, Santiago, pp. 39-124. 
luego de la reforma constitucional de agosto de 2005, se ubica en el capítulo octavo de la Constitución, artículos 92 a 94.

Las competencias del Tribunal Constitucional se caracterizan por ser de carácter taxativo, exclusivas, improrrogables e indelegables y de ejercicio inexcusable.

Las competencias del Tribunal Constitucional están expresamente señaladas en el texto de la Carta Fundamental por lo cual ellas no pueden ser alteradas por el legislador. Dichas competencias han evolucionado en el tiempo, siendo únicamente las que el texto constitucional señala.

Tales competencias están contempladas durante el periodo que transcurre entre 1981 hasta 2005, en el artículo 82 de la Constitución, ${ }^{23}$ ellas se amplían respecto del texto de la Carta de 1925, el control de constitucionalidad de normas jurídicas abarca nuevas materias, además de las ya contempladas en el texto de la Constitución de 1925, reformada en 1970, ellas son las siguientes: la resolución de las cuestiones de constitucionalidad que se susciten respecto de un proyecto de reforma constitucional (artículo 82 № 2); el control obligatorio y preventivo de constitucionalidad de las leyes orgánicas constitucionales antes de su promulgación y de las leyes que interpretan algún precepto de la Constitución (artículo 82 № 1); resolver las cuestiones que se susciten sobre la constitucionalidad de un decreto con fuerza de ley (artículo 82 № 3); resolver los reclamos en caso de que el Presidente de la República dicte un decreto inconstitucional (artículo 82 № 5); resolver sobre la constitucionalidad de un decreto 0 resolución del Presidente de la República que la Contraloría haya representado por estimarlo inconstitucional, cuando sea requerido por el Presidente (artículo 82 № 6); resolver sobre la Constitucionalidad de los decretos supremos dictados en ejercicio de la potestad reglamentaria del Presidente de la República, cuando ellos se refieran a materias que pudieren estar reservadas a la ley por mandato del artículo 60 de la Constitución (artículo 82 № 12).

A umenta también el ámbito de las competencias en materia de organización institucional, ya que además de las contempladas en la Carta de 1925 referentes a las inhabilidades constitucionales y legales que afectaren a una persona para ser designada M inistro de Estado, permanecer en dicho cargo o desempeñar simultáneamente otras funciones, se agregan las de pronunciarse sobre las inhabilidades, incompatibilidades y causales de cesación en el cargo de los parlamentarios (artículo 82 № 11) y la de informar al Senado en los casos en que éste deba pronunciarse declarando la inhabilidad del Presidente de la República o del Presidente Electo cuando un impedimento físico o mental lo inhabilite para el ejercicio de sus funciones o declarar si los motivos en que se origina la dimisión del Presidente de la República son o no fundados y, en consecuencia, admitirla o desecharla (artículo 82 № 9).

23 Veren el mismo sentido Rios, Lautaro (1988). La Justicia Constitucional en Chile, p. 69. Rivera NeumanN, Teodoro (1989). Tribunal Constitucional y su aporte al derecho, p. 197. SILVA BAsCuÑÁn, Alejandro (2003). Tratado de Derecho Constitucional, Tomo IX, Editorial Jurídica de Chile, Santiago, Chile, pp. 58-184. 
Sin embargo, el constituyente de 1980 resta al Tribunal Constitucional la competencia que le había otorgado el constituyente derivado de 1970 de resolver las contiendas de competencias que determinarán las leyes, que es una atribución de la esencia de un Tribunal Constitucional.

Por último, el constituyente de 1980 le entregó un ámbito competencial nuevo, de carácter sancionador, como es el de declarar la inconstitucionalidad de las organizaciones y de los movimientos o partidos políticos, como asimismo, determinar la responsabilidad y sanción de las personas que hubieren tenido participación en los hechos que motivaron la declaración de inconstitucionalidad, los cuales, de acuerdo al artículo 19 № 15, inciso sexto, son los actos o conductas que no respetan los principios básicos del régimen democrático y constitucional, procuran el establecimiento de un sistema totalitario, como asimismo aquellos que hagan uso de la violencia, la propaguen o inciten a ella como método de acción política. Si la persona responsable del ilícito constitucional fuere el Presidente de la República o el Presidente electo, la referida declaración requerirá, además, el acuerdo del Senado adoptado por la mayoría de sus miembros en ejercicio (artículo 82 № 7).

La inexcusabilidad del ejercicio de sus competencias por parte del Tribunal Constitucional estaba contemplada en el artículo 73 del texto original, hoy artículo 76 de la Constitución reformada en 2005, como asimismo en su propia ley orgánica constitucional del Tribunal Constitucional. La incompetencia por falta de jurisdicción la resuelve el propio Tribunal Constitucional, de acuerdo al artículo 18 de la ley $N^{\circ} 17.997$ Orgánica del Tribunal Constitucional, cuya ley adecuatoria a la reforma se encuentra en trámite parlamentario hasta agosto de 2008.

La reforma constitucional de agosto de 2005 concentró el control de constitucionalidad sobre normas jurídicas en el Tribunal Constitucional, lo cual constituye un cambio de modelo de jurisdicción constitucional, el cual tiene importantes consecuencias en el sistema de defensa del orden constitucional. Se mantienen en los tribunales ordinarios la jurisdicción constitucional de la libertad, vale decir, las acciones de amparo (Habeas Corpus) y de Protección (Amparo o tutela en el derecho comparado), además debe tenerse presente que la Corte Suprema en materia procesal penal es competente para pronunciarse en el recurso de nulidad por vulneración de derechos fundamentales.

El texto del artículo 92 de la Carta Fundamental de acuerdo a la reforma constitucional aprobada el 26 de agosto de $2005,{ }^{24}$ establece una nueva integración del Tribunal Constitucional, aumentando su integración de siete a diez miembros, eliminando la anterior integración de miembros designados por el Consejo de Seguridad Nacional, además de aumentar la integración proveniente por el Presidente de la República

24 Ley N ${ }^{\circ} 20.050$ de Reforma Constitucional, publicada en el Diario O ficial del 26 de agosto de 2005. Por Decreto $\mathrm{N}^{\circ} 100$ publicado en el Diario Oficial del 22 de septiembre de 2005 , se fija el texto refundido y sistematizado de la Constitución Política de la República. Ver texto en www.cecoch.cl/materiales 
y del Congreso Nacional, incorporando a la Cámara de Diputados en el proceso de nombramiento de algunos de los nuevos M inistros del Tribunal:

“Artículo 92. Habrá un Tribunal Constitucional integrado por diez miembros, designados de la siguiente forma:

a) Tres designados por el Presidente de la República

b) Cuatro elegidos por el Congreso Nacional. Dos serán nombrados directamente por el Senado y dos serán previamente propuestos por la Cámara de Diputados para su aprobación o rechazo por el Senado. Los nombramientos, o la propuesta en su caso, se efectuarán en votaciones únicas y requerirán para su aprobación del voto favorable de los dos tercios de los senadores o diputados en ejercicio, según corresponda.

c) Tres elegidos por la Corte Suprema en una votación secreta que se celebrará en sesión especialmente convocada para tal efecto.

Los miembros del Tribunal durarán nueve años en sus cargos y se renovarán por parcialidades cada tres. Deberán tener a lo menos quince años de título de abogado, haberse destacado en la actividad profesional, universitaria o pública, no podrán tener impedimento alguno que los inhabilite para desempeñar el cargo de juez, estarán sometidos a las normas de los artículos 55, 56 y 78, y no podrán ejercer la profesión de abogado ni actuar como procurador o agente en gestiones particulares de carácter administrativo.

Los miembros del Tribunal Constitucional serán inamovibles y no podrán ser reelegidos, salvo aquél que lo haya sido como reemplazante y haya ejercido el cargo por un período menor a cinco años. Cesarán en sus funciones al cumplir 75 años de edad, además precisa las materias que serán objeto de competencia del pleno del Tribunal Constitucional y el quórum necesario para sesionar y adoptar resoluciones:

"El Tribunal resolverá en pleno las cuestiones indicadas en los números 1운 3ㄴ, 4, $50,60,70,80,90$ y $12^{\circ}$ del artículo siguiente. Para el ejercicio de sus restantes atribuciones podrá funcionar en pleno o en sala de acuerdo a lo que disponga la ley orgánica constitucional. El quórum para sesionar será de, a lo menos, cuatro quintos de sus respectivos miembros. El Tribunal adoptará sus acuerdos por simple mayoría, salvo los casos en que se exija un quórum diferente y fallará de acuerdo a derecho".

A su vez, el artículo 81 determina que "Una ley orgánica constitucional determinará su organización y funcionamiento, así como sus atribuciones y procedimiento y fijará la planta, régimen de remuneraciones y estatuto de su personal".

El ámbito de competencias del control de constitucionalidad desarrollado por los tribunales constitucionales generalmente se clasifica en cuatro materias:

A. Control de constitucionalidad normativa u orgánica.

B. Control de constitucionalidad de conflictos de atribuciones o competencias. 


\begin{abstract}
C. Control de constitucionalidad a través del amparo de derechos fundamentales y sus garantías.

D. Otras competencias o competencias residuales.
\end{abstract}

\title{
A. El control de constitucionalidad normativo.
}

El control de constitucionalidad normativo lo clasificaremos y analizaremos atendiendo a si este se desarrolla en forma (1) preventiva o en forma (2) represiva.

a) El control de constitucionalidad sobre normas realizado de forma preventiva. El control preventivo busca evitar la vigencia y aplicación de normas inconstitucionales, aplicándose a los preceptos legales o de reforma constitucional, antes de su promulgación y respecto de tratados internacionales antes de su ratificación. Además, en materia de tratados, existe el efecto de evitar la trasgresión de la Convención de Viena sobre Derecho de los Tratados de 1969, en especial los artículos 26 y 27, que los Estados han incorporado a sus ordenamientos jurídicos, los cuales establecen que "todo tratado en vigor obliga a las partes y debe ser cumplido por ellas de buena fe" (art. 26); "que una parte no podrá invocar las disposiciones de derecho interno como justificación del incumplimiento de un tratado" (art. 27). De esta manera, para actuar de buena fe en el cumplimiento de las obligaciones jurídicas contraídas en el ámbito del derecho internacional, es necesario con un mínimo de coherencia lógica y jurídica, que los Estados establezcan un control sólo preventivo pero obligatorio de constitucionalidad de todos los tratados internacionales que se deseen incorporar al derecho interno.

\section{El control preventivo de constitucionalidad de reformas constitucionales y del ejercicio del poder constituyente derivado o instituido.}

La Constitución chilena precisa el control de constitucionalidad de los proyectos de reforma constitucional en su artículo $93 \mathrm{~N} N$ o 3, a requerimiento del Presidente de la República, de cualquiera de las Cámaras o de una cuarta parte al menos de sus miembros en ejercicio, que sean formuladas antes de la promulgación del proyecto de reforma constitucional.

En el caso chileno, el control de constitucionalidad, además de los aspectos procedimentales 0 adjetivos se extiende a los aspectos sustantivos, en virtud de que, de acuerdo al artículo 5 ㅇ inciso $2^{\circ}$, el ejercicio de la potestad constituyente tiene como límite los derechos esenciales de las personas aseguradas por la Constitución como asimismo, por los tratados ratificados por Chile y vigentes. En Chile hay así una concreción constitucional del principio de irreversibilidad en materia de derechos esenciales, el que, a su vez, está contenido también en el artículo 29 literales a) y b) de la Convención A mericana de Derechos Humanos, en el sentido de que ninguna disposición puede ser interpretada en el sentido de permitir suprimir el goce y ejercicio de los derechos y libertades reconocidos o limitados en mayor medida que lo previsto en la Convención o en el ordenamiento jurídico de los Estados Partes o de otra Convención en que sea parte el Estado. 
Estos principios de interpretación obligan a una concepción progresiva en el respeto, garantía y promoción de los derechos por los órganos constituidos.

A simismo, nos parece que otra limitación material al poder constituyente derivado es que este no puede transformar el sistema institucional republicano democrático en un régimen autocrático, desvirtuando el aseguramiento de los derechos fundamentales, su sistema de protección jurídica y jurisdiccional, como asimismo, no podrían eliminarse los controles del poder político y la separación de funciones estatales, una reforma constitucional que vulnerara dichos principios y reglas constitucionales, realizaría una mutación inconstitucional y contraria a derecho del orden constitucional, la que podría regir sólo por la fuerza de los hechos, pero no por la fuerza del derecho, siendo esencialmente antijurídica, ${ }^{25}$ al constituir una tiranía de la mayoría como en su momento señaló Alexis de Tocqueville. ${ }^{26}$

\section{El control preventivo de constitucionalidad de los tratados o convenciones internacionales.}

En el caso chileno, el artículo 82 № 2 de la Constitución vigente desde marzo de 1981 hasta 2005, precisaba el control preventivo facultativo de los tratados internacionales sometidos a la aprobación del Congreso, el que se concreta a petición de cualquiera de las dos cámaras (Cámara de Diputados o Senado) o por, al menos, una cuarta parte de los diputados o senadores en ejercicio.

La reforma constitucional de agosto de 2005 establece en el artículo $93 \mathrm{~N}^{\circ} 1$ el control preventivo obligatorio respecto de los tratados que se refieren a materias propias de ley orgánica constitucional, dejando en el resto de las materias un control preventivo facultativo en los términos señalados en el párrafo anterior, todo ello de acuerdo al nuevo artículo $93 \mathrm{~N}^{\circ} 3$.

Ello nos merece la consideración crítica de que debieran ser todos los tratados internacionales los que debieran someterse a control preventivo obligatorio de constitucionalidad, con el objeto de dotar de plena seguridad jurídica a dichos instrumentos jurídicos una vez incorporados al derecho interno y ser coherente con la obligación de los Estados Partes de los tratados de cumplirlos de buena fe, sin oponer obstáculos de derecho interno a ello, de acuerdo a lo dispuesto en los artículos 26, 27 y 31 de la Convención de Viena sobre Derecho de los Tratados, quedando a salvo, luego de la incorporación del tratado al derecho interno, la facultad del Estado de denunciar el tratado internacional de acuerdo a las reglas del propio tratado o de acuerdo con las normas generales del derecho internacional.

25 Ver al respecto, Nogueira Alcalá, Humberto (1990). "La democracia, el orden constitucional democrático y las reglas de su modificación", en XX Jornadas de Derecho Público, Tomo I, Ed. Edeval, Valparaíso, p. 85.

26 Tocqueville, Alexis de (1984). La Democracia en A mérica, Fondo de Cultura Económica, M éxico, pp. 254 y sS. 
En el caso chileno, el texto constitucional no establece una regulación constitucional adecuada acerca de la ubicación de los tratados en el sistema de fuentes, ni tampoco sobre la fuerza aplicativa de tales normas jurídicas, siendo urgente abordar dicha materia en una perspectiva contemporánea y en el contexto de un mundo globalizado y de procesos de integración, donde la concepción tradicional de soberanía no resiste el derecho internacional de los derechos humanos y la transferencia de competencias a órganos políticos y jurisdiccionales supranacionales. ${ }^{27}$

La reforma constitucional de 2005 en esta materia ha sido muy pobre, solamente se obtuvo el consenso necesario para establecer en el nuevo artículo 54 de la Carta Fundamental, incisos $6^{\circ}$ y $7^{\circ}$ lo siguiente:

“Las disposiciones de un tratado sólo podrán ser derogadas, modificadas o suspendidas en la forma prevista en los propios tratados o de acuerdo a las normas generales del derecho internacional.

“Corresponde al Presidente de la República la facultad exclusiva para denunciar un tratado o retirarse de él, para lo cual pedirá la opinión de ambas Cámaras del Congreso, en el caso de tratados que hayan sido aprobados por éste. Una vez que la denuncia o el retiro produzca sus efectos en conformidad a lo establecido en el tratado internacional, éste dejará de tener efecto en el orden jurídico chileno.".

En el contexto sudamericano los sistemas de control de constitucionalidad de tratados que se adecuan de mejor forma a una perspectiva armónica del derecho interno y derecho internacional, como asimismo, al cumplimiento de buena fe de las obligaciones válidamente contraídas por los Estados, sin oponer a ellos obstáculos de derecho interno que son expresión del propio poder estatal son, sin duda, los establecidos en las Constituciones de Colombia y Ecuador por ser un control preventivo obligatorio respecto de todos los tratados internacionales, control que impide que se produzcan conflictos entre derecho interno y derecho internacional.

Consideramos que un tratado o convención internacional ratificado y con las comunicaciones de ratificación canjeadas o cumpliendo las disposiciones de los artículos 11 y 24 de la Convención de Viena sobre Derecho de los Tratados, desarrollado por los órganos competentes, sin que exista un reparo previo de constitucionalidad, habiéndose integrado el tratado o convención al ordenamiento jurídico interno, es adecuado considerar la inexistencia de control represivo de constitucionalidad, por razones de seguridad jurídica, de respeto a los actos propios, de respeto al honor del Estado, de cumplimiento de los compromisos internacionales, quedando solamente como alternativa legítima y viable la denuncia de la Convención o tratado de acuerdo con las reglas del derecho internacional. ${ }^{28}$

27 Ver Nogueira Alcalá, Humberto (2002). "Consideraciones sobre el fallo del Tribunal Constitucional respecto del Tratado de Roma que establece la Corte Penal Internacional", Revista Ius et Praxis, año 8 № 1 , Facultad de Ciencias Jurídicas, Universidad de Talca, pp. 563 y ss.

28 Sobre la materia ver el interesante trabajo de BAZÁn, Víctor (2003). Jurisdicción constitucional y control de constitucionalidad de los tratados internacionales. Un análisis de derecho comparado, Editorial Porrúa, M éxico. 
El proyecto de Ley Orgánica Constitucional del Tribunal Constitucional en sus fundamentos determina: "Respecto de los tratados, se establece que el requerimiento debe hacerse antes de que sea remitida la comunicación en que se informa al Presidente que el tratado fue aprobado por el Congreso, o en los cinco días inmediatamente siguientes. Pero, durante este último plazo, el requerimiento no se admitirá si el Presidente ya hubiere ratificado el tratado".

\section{El control preventivo de constitucionalidad de preceptos legales y otras nor- mas infraconstitucionales.}

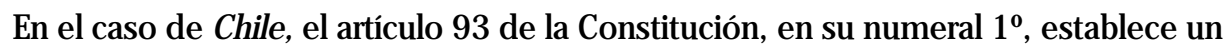
control preventivo obligatorio de constitucionalidad sobre proyectos de leyes interpretativas de la Constitución y leyes orgánicas constitucionales, antes de su promulgación.

Dicho requerimiento tiene una legitimación activa restringida, la que puede ser desarrollada por el Presidente de la República, cualquiera de las dos ramas del Congreso Nacional o, a lo menos, una cuarta parte de los diputados o senadores en ejercicio.

Dicho control preventivo de constitucionalidad puede versar sobre aspectos de forma como de fondo.

El proyecto de Ley Orgánica Constitucional del Tribunal Constitucional, con la finalidad de precisar la oportunidad definida por la Constitución, para plantear el requerimiento (antes de la promulgación), establece que la promulgación de los proyectos se entiende efectuada por el Presidente de la República cuando ingrese a la oficina de partes de la Contraloría General de la República el respectivo decreto promulgatorio. No se podrá admitir a tramitación requerimientos formulados con posterioridad a ese instante.

b) El control represivo o correctivo de constitucionalidad de normas jurídicas por los tribunales constitucionales. El control represivo, correctivo o a posteriori se concreta cuando la norma impugnada ya forma parte del ordenamiento jurídico, pudiendo ser impugnada en la forma o en el fondo, como asimismo por inconstitucionalidad sobreviniente, pudiendo adoptar distintas modalidades y vías.

\section{El juicio incidental de inconstitucionalidad de preceptos legales ante el Tribu- nal Constitucional.}

El traspaso del control de inaplicabilidad por inconstitucionalidad en control reparador concreto de la Corte Suprema al Tribunal Constitucional, se debió a la fuerte crítica de la doctrina académica y de los operadores jurídicos al mal desempeño de la Corte Suprema en el ejercicio de su competencia proveniente, ya de la Carta de 1925 y mantenida en el texto original de la Carta de 1980 hasta 2005, la cual considera la autolimitación de la Corte Suprema en la materia, como asimismo, el no haber entendido correctamente sus facultades, donde a menudo confundía el control abstracto con el control concreto de constitucionalidad de preceptos legales. La otra razón fundamental de la reforma es generar un parámetro único de control jurisdiccional de 
constitucionalidad de preceptos legales, ya que en nuestro ordenamiento constitucional hasta el año 2005, en la materia, existían dos parámetros de control, uno determinado por el Tribunal Constitucional en control preventivo y otro generado por la Corte Suprema en control reparador concreto, los cuales no eran coincidentes, lo que afectaba fuertemente la seguridad jurídica requerida en todo Estado Constitucional, como asimismo, una desigualdad en la aplicación de la ley conforme a la Constitución.

La reforma constitucional de 2005, al traspasar el control de constitucionalidad que ejercía la Corte Suprema a través del recurso de inaplicabilidad por inconstitucionalidad en control reparador concreto por vía incidental, según determinaba el artículo 80 de la Carta Fundamental en su versión pre reforma constitucional, posibilitó que no sólo pudieran requerir el pronunciamiento del Tribunal Constitucional la parte en la gestión judicial que considerara que la aplicación de un precepto legal en la resolución del caso genera una norma inconstitucional, sino también abrió la posibilidad que no tenían los magistrados ordinarios o especiales bajo el texto constitucional anterior a la reforma, para que el magistrado quedara liberado de aplicar un enunciado normativo legal que generara una norma que resolviera la gestión de dudosa constitucionalidad o un resultado que considere abiertamente inconstitucional, posibilitando que recurra al Tribunal Constitucional para que declare en el caso concreto la inaplicabilidad, aun cuando ello no sea solicitado por ninguna de las partes.

Así, la legitimación activa para plantear la cuestión de inconstitucionalidad en un proceso, que, en principio, correspondía a las partes del procedimiento, la reforma constitucional de 2005 innovó en la materia, al posibilitar la legitimación activa ya no sólo a las personas que tengan un interés concreto o un derecho específico comprometido, sino que también posibilita que el juez plantee el problema, quien puede plantearse la cuestión de inconstitucionalidad de la ley de oficio, por lo que debe considerarse que tiene legitimación activa para hacerlo.

En tal caso, la reforma siguió, en este aspecto concreto, un acercamiento al modelo de control concentrado europeo, de control reparador concreto por vía incidental (cuestión de inconstitucionalidad o juicio incidental de inconstitucionalidad) existente en Portugal, en Europa, como asimismo de Guatemala y de la Sala Constitucional de la Corte Suprema en Paraguay, en A mérica Latina. El constituyente chileno se diferenció del procedimiento incidental establecido en las Constituciones alemana, italiana y española en Europa y del caso de Bolivia en Sudamérica, ya que en estos últimos casos el control incidental genera efectos erga omnes y no sólo efectos inter partes como en el caso chileno y los modelos antes señalados.

El artículo 93 (ex artículo 82) numeral $6^{\circ}$, establece como competencia del Tribunal Constitucional, "resolver, por la mayoría de sus miembros en ejercicio, la inaplicabilidad de un precepto legal cuya aplicación en cualquier gestión que se siga ante un tribunal ordinario o especial, resulte contraria a la Constitución". 
La reforma constitucional en su artículo $93 \mathrm{~N}^{\circ} 6$ establece un mecanismo de control de constitucionalidad de tipo concentrado, ya que la Carta Fundamental entrega dicha competencia en forma exclusiva al Tribunal Constitucional. Dicha facultad está vedada para los órganos jurisdiccionales inferiores, quienes tienen el deber de elevar los antecedentes al Tribunal Constitucional para que se pronuncie en la materia.

El juicio incidental de inconstitucionalidad permite conjugar dos principios constitucionales básicos, la eficacia directa de la Constitución y el principio de respeto a la ley por parte de los tribunales ordinarios, posibilitando al tribunal ordinario elevar a la consideración del Tribunal Constitucional todo precepto legal en el cual haya dudas de constitucionalidad.

Ella contribuye a establecer un diálogo y una colaboración entre tribunales ordinarios y Tribunal Constitucional, permite concretar con eficacia la fuerza normativa de la Constitución, su supremacía y defensa, como asimismo, salvar el principio que prohibía a los jueces letrados y Cortes de A pelaciones inaplicar por sí mismo un precepto legal post constitucional o de dudosa constitucionalidad, ya que dicha facultad estaba reservada en forma exclusiva a la Corte Suprema por el artículo 80 de la Constitución, atribución que desaparece con la reforma constitucional que se está aprobando.

Debemos entender por preceptos legales, todas las normas jurídicas que emanan de la potestad unilateral del Estado, que han sido elaborados conforme al procedimiento contemplado en los artículos 63 a 75 de la Constitución vigente, vale decir, los que nuestra Carta Fundamental denomina leyes (leyes ordinarias, leyes de quórum calificado; leyes orgánicas constitucionales, leyes de habilitación legislativa, decretos con fuerza de ley, leyes especiales). Además se incluyen los Decretos Leyes emanados de los gobiernos de facto, que los órganos constitucionales posteriormente no han dejado sin efecto, reconociéndoles eficacia jurídica y fuerza normativa de ley.

No entran en la categoría de preceptos legales las convenciones o tratados internacionales ya que ellos surgen de la voluntad de dos o más Estados u organismos internacionales, generándose en el ámbito del derecho internacional y no del derecho interno del Estado, cuya validez y fuerza normativa se rige por el derecho internacional. El Estado unilateralmente sólo puede incorporarlo a su ordenamiento jurídico, dándole aplicabilidad preferente sobre las normas de derecho interno, no pudiendo unilateralmente invalidarlo, inaplicarlo, reformarlo, todo lo cual sólo puede concretarse de acuerdo con las normas vigentes del derecho internacional.

Por ello, el gobierno en su motivación original del proyecto de Ley Orgánica Constitucional del Tribunal Constitucional fundamenta la imposibilidad que el Tribunal Constitucional pueda declarar inaplicable o inconstitucional un precepto contenido en un tratado o convención internacional, posición que suscribimos enteramente, al respecto se precisa:

"el proyecto excluye la posibilidad de impugnar tratados internacionales mediante la cuestión de inaplicabilidad. Esta exclusión tiene varios fundamentos. Desde luego, los tratados no son producto del ejercicio de una potestad legisla- 
tiva. La Constitución considera la aprobación de tratados como una facultad del Congreso Pleno (art. 54). La potestad legislativa se ejerce por la Cámara y el Senado, que "concurren a la formación de las leyes" (art. 46). El Congreso no puede ejercer la plenitud de sus potestades legislativas respecto de un tratado, como lo hace respecto de una ley, pues sólo puede aprobar o rechazar íntegramente el texto ya negociado por el Presidente de la República. Enseguida, a los tratados no se les aplican todos los trámites de una ley, sino únicamente, como establece la Constitución, "en lo pertinente". Por ejemplo, no cabe el tercer trámite, ni la Comisión Mixta, ni la facultad de presentar indicaciones. El propio Tribunal Constitucional ha reconocido que los tratados están en una categoría intermedia entre la Constitución y la ley, no siendo, en consecuencia, "preceptos legales". Es sobre estos actos que recae la inaplicabilidad.

"A dicionalmente, una vez que el tratado se incorpora al orden jurídico interno, es el propio tratado o el derecho internacional el que define sus formas de derogación, modificación o suspensión. Ello excluye la posibilidad de que un Tribunal nacional dicte una orden de inaplicar un tratado en un caso concreto, porque tal orden sería una "suspensión" de un tratado vigente.

"En plena concordancia con lo dicho, la Constitución sólo contempló la intervención del Tribunal Constitucional en el caso del control preventivo obligatorio de los tratados, pero no el control represivo vía inaplicabilidad o declaración de inconstitucionalidad. La primera provocaría una suspensión del tratado vigente, mientras que la segunda produciría la derogación del mismo, lo que resulta abiertamente incompatible con lo dispuesto en el artículo 54 de la Constitución. Este precepto establece que las disposiciones de un tratado sólo pueden ser derogadas "en la forma prevista en el tratado o en las normas previstas en el derecho internacional".

"De este modo, lo que está en juego es si un órgano interno puede disponer la suspensión o derogación de una norma pactada con uno o varios Estados u organismos internacionales. Por una regla de prudencia, entonces, se ha estimado más conveniente excluirlos de la inaplicabilidad".

Dicha fundamentación da lugar al artículo $47 \mathrm{~B}$, el cual determina: “De conformidad al artículo 54 número $1^{\circ}$, no procederá la inaplicabilidad respecto de tratados internacionales ratificados por Chile y que se encuentren vigentes".

\footnotetext{
El control reparador, abstracto, con efecto erga omnes de inconstitucionalidad practicado de oficio por el Tribunal Constitucional.

El Congreso Nacional había aprobado en esta materia que, después de que el Tribunal Constitucional se hubiera pronunciado sobre la inaplicabilidad de un precepto legal, inmediatamente a través de un control automático de oficio, el pleno del Tribunal debía pronunciarse sobre la expulsión del precepto legal considerado inaplicable del ordenamiento jurídico.
}

El Presidente de la República a través del veto $\mathrm{N}^{\circ} 18$ respecto del proyecto de reforma constitucional aprobada por el Congreso realiza "una pequeña pero relevante precisión en materia de procedimiento", según manifiesta el propio veto. 
Esta precisión es explicada en el fundamento del veto presidencial en los siguientes términos:

"La norma aprobada establece que el juicio de constitucionalidad debe hacerse "en el mismo fallo en que haya declarado inaplicable un precepto legal".

"Esta última solución impediría la alternativa de una vista de la causa con el objeto de solicitar opinión a los órganos democráticos del Estado que generaron la ley. Este procedimiento es esencial puesto que el acto que caracteriza la expresión suprema del poder de los modernos Tribunales Constitucionales radica en su capacidad de declarar la inconstitucionalidad de una ley. Este poder ha sido cuestionado doctrinariamente por constituir un poder contramayoritario o un contrapoder democrático. No obstante, como reseña un autor, es perfectamente conciliable con la democracia puesto que a diferencia de los demás órganos del Estado que existen para algo, la tarea del Tribunal Constitucional no es hacer el bien sino evitar que se haga el mal, entendido éste como la actuación de los demás poderes al margen de lo previsto en la Constitución. Es un órgano defensivo del Estado Democrático frente a su posible desnaturalización. Por lo mismo, en su tarea de declarar la inconstitucionalidad ha de actuar con la debida prudencia y ejercicio de ultima ratio que dicha fórmula exige.

“En este sentido, el veto $\mathrm{N}^{\circ} 18$ declara que debe distinguirse netamente el juicio de inaplicabilidad del juicio de inconstitucionalidad. Debe, por ende, establecerse un procedimiento que articule este último juicio y para ello se remiten parte de sus aspectos a la regulación por la ley orgánica constitucional respectiva.

"A simismo, se abre un limitado espacio a una acción pública, para pedir la declaración de inconstitucionalidad sólo una vez declarada la inaplicabilidad por parte del Tribunal. En este caso, se puede proceder a un nuevo examen de admisibilidad de la acción con el objeto de limitar las múltiples acciones sobre asuntos similares. De la misma manera, se mantiene la capacidad del propio Tribunal para proceder de oficio".

El texto propuesto en el veto fue aprobado por ambas ramas del Congreso Nacional, constituyendo así en el nuevo texto constitucional, el cual quedó redactado de la siguiente forma:

"70 Resolver por la mayoría de los cuatro quintos de sus integrantes en ejercicio, la inconstitucionalidad de un precepto legal declarado inaplicable en conformidad a lo dispuesto en el numeral anterior;".

La legitimación activa queda radicada así en cualquier ciudadano, pudiendo este requerir al Tribunal Constitucional la expulsión del ordenamiento jurídico de cualquier precepto legal que haya sido previamente declarado inaplicable por el propio Tribunal en control concreto.

Asimismo, la Constitución prevé que el propio Tribunal Constitucional puede, de oficio, pronunciarse sobre la inconstitucionalidad de un precepto legal previamente declarado inaplicable en control concreto, todo ello de acuerdo con las normas que 
regulen la materia que contendrá la reforma a la Ley Orgánica Constitucional del Tribunal Constitucional.

El tema de la admisibilidad de las acciones populares de inconstitucionalidad estará regulado en la Ley Orgánica Constitucional, sin perjuicio de lo cual, el texto constitucional determina al menos dos requisitos: la previa declaratoria de inaplicabilidad por el Tribunal Constitucional y el establecimiento de argumentos jurídicos que hagan razonable el control abstracto que debe practicar el Tribunal Constitucional señalando las disposiciones constitucionales vulneradas por el precepto legal y que éste en cualquiera de sus interpretaciones posibles sea inconstitucional.

El Tribunal Constitucional al examinar el precepto legal cuestionado en control abstracto, deberá notificar a los órganos constitucionales concernidos, como son el Presidente de la República y ambas Cámaras del Congreso Nacional, los que podrán apersonarse en el procedimiento en cuanto órganos colegisladores, dando a conocer sus razonamientos y fundamentos sobre la constitucionalidad del precepto legal aprobado por ellas y aún vigente, todo ello dentro de normas que garanticen un debido proceso constitucional.

En todo caso, como lo explicita claramente el fundamento del veto presidencial al texto aprobado por el Congreso Nacional siempre debe asegurarse un debido proceso constitucional.

"En el veto $N^{\circ} 14$ se precisa la interpretación de una materia al mandato de regulación del Tribunal Constitucional....

"En el primer caso, se quiere dejar expresa constancia que la expresión "procedimientos", permite organizar el debido proceso al interior de la tramitación de algunas de las competencias del Tribunal Constitucional en aquello no previsto por la propia Constitución. Es así como se puede verificar en qué consistirá el examen de admisibilidad en casos determinados, una orden de no innovar u ordenar la tramitación y vista de la causa cuando sea necesario".

El Tribunal Constitucional deberá pronunciarse en Pleno sobre la inconstitucionalidad en abstracto, en la medida que en tal control considere que el precepto legal cuestionado debe ser expulsado del ordenamiento jurídico por inconstitucionalidad de forma o fondo.

Enseguida, el Tribunal debe dictar sentencia dentro del plazo de treinta días y sólo en casos calificados y por resolución fundada, puede prorrogarlo por otros quince días.

Cabe señalar que el Tribunal puede fundar la declaración de inconstitucionalidad de las normas legales cuestionadas, únicamente en la infracción de los preceptos constitucionales que fueron considerados transgredidos en la sentencia previa que le sirva de sustento. Con ello no se hace más que establecer claramente la vinculación entre la inaplicabilidad y la inconstitucionalidad. 
Finalmente, la sentencia que declare la inconstitucionalidad de todo o parte de un precepto legal, debe publicarse, en extracto, en el Diario Oficial dentro de los tres días siguientes a su dictación.

La fórmula propuesta no nos parece que sea la más adecuada, el Tribunal Constitucional debiera poder examinar la constitucionalidad del precepto legal, siendo la Constitución y el bloque constitucional de derechos el parámetro para determinar si el precepto legal es o no compatible con ella, analizando las diversas hipótesis posibles por las cuales los preceptos legales pueden ser inconstitucionales, considerando no solo las normas constitucionales citadas como infringidas por el actor, sino examinando la conformidad del o los preceptos legales con todas las normas que constituyen parámetro de control de constitucionalidad, ya que el Tribunal se presume que conoce el derecho vigente y lo aplica, por lo tanto, la decisión de inconstitucionalidad debiera poder basarse en cualquier disposición constitucional que haya sido infringida por el precepto legal que haya sido cuestionado por el actor.

La decisión del Tribunal Constitucional solo podrá determinar la expulsión del ordenamiento jurídico del o los preceptos legales cuestionados en su constitucionalidad, si se pronuncian en tal sentido al menos los cuatro quintos de los Ministros en ejercicio.

Dicho quórum nos parece exagerado, ya que posibilita que un criterio minoritario al interior del Tribunal pueda bloquear la determinación de la mayoría absoluta de los M inistros que componen dicho Tribunal. Ello establece la parad oja que el criterio jurídico de la minoría vale más que el criterio jurídico de la mayoría de los M inistros del Tribunal Constitucional, posición que constituye una "rara avis" dentro del derecho constitucional comparado, ya que expresa una desconfianza en el criterio jurídico de la mayoría absoluta del Tribunal Constitucional como defensor de la Constitución.

\section{El control de constitucionalidad de los Autos Acordados dictados por la Corte Suprema de Justicia, las Cortes de Apelaciones y el Tribunal Calificador de Elec- ciones.}

De acuerdo al artículo 93 № 2, el Tribunal Constitucional resuelve sobre las cuestiones de constitucionalidad de los Autos A cordados dictados por la Corte Suprema, las Cortes de A pelaciones y el Tribunal Calificador de Elecciones.

En este caso la legitimación activa corresponde al Presidente de la República, a cualquiera de las Cámaras o a diez de sus miembros.

La Constitución franquea la legitimación activa también a cualquier persona que sea parte en juicio o gestión pendiente ante un tribunal ordinario o especial, o desde la primera actuación en el procedimiento penal, cuando sea afectado en el ejercicio de sus derechos fundamentales por lo dispuesto en el respectivo auto acordado. 
El proyecto de LOC del Tribunal Constitucional, en el artículo 37 c), dispone que la interposición del requerimiento no suspenderá la aplicación del auto acordado impugnado.

A su vez, el artículo 37 D, precisa que, admitido a tramitación, se comunicará a la Corte Suprema, a la Corte de A pelaciones respectiva o al Tribunal Calificador de Elecciones, según corresponda, enviándoles copia del requerimiento, para que, en el plazo de diez días, hagan llegar al Tribunal las observaciones y los antecedentes que estimen necesarios.

La sentencia deberá dictarse en el plazo de quince días. Sólo excepcionalmente y por razones fundadas, el Tribunal podrá declarar la inconstitucionalidad de las normas cuestionadas en la infracción de un precepto constitucional distinto al invocado en el requerimiento. Asimismo, el artículo $37 \mathrm{f}$ ) dispone que la sentencia que declare la inconstitucionalidad de todo o parte de un auto acordado, la publicará en extracto en el Diario Oficial dentro de los tres días siguientes a su dictación. Desde dicha publicación, el auto acordado, o la parte de él que hubiere sido declarada inconstitucional, se entenderá derogado, lo que no producirá efecto retroactivo.

Finalmente, el artículo $37 \mathrm{G}$ precisa que "Habiéndose pronunciado el Tribunal sobre la constitucionalidad de un auto acordado, no se admitirá a tramitación ningún requerimiento para resolver sobre cuestiones de constitucionalidad del mismo auto acordado, a menos que se invoque un vicio distinto que el hecho valer con anterioridad".

\section{El control represivo abstracto de decretos con fuerza de ley.}

En el caso de Chile, el artículo 93 № 4 de la Constitución posibilita un control represivo abstracto de los decretos con fuerza de ley.

El control reparador de constitucionalidad respecto de decretos supremos.

El artículo $93 \mathrm{~N}^{\circ} 16$ que establece el control reparador de los decretos supremos, "cualquiera sea el vicio invocado, incluyendo aquellos que fueren dictados en el ejercicio de la potestad reglamentaria autónoma del Presidente de la República cuando se refieran a materias que pudieran estar reservadas a la ley por mandato del artículo 63".

Este control represivo sobre decretos con fuerza de ley lo puede solicitar cualquiera de las Cámaras, Cámara de Diputados o Senado, o una cuarta parte al menos de los diputados o senadores en ejercicio, cuando la Contraloría General de la República haya tomado razón de una norma considerada inconstitucional.

En el caso de la impugnación de decretos supremos por incidir en materia reservada a la ley por el artículo 60 de la Carta Fundamental, ello puede concretarse solo por cualquiera de las dos Cámaras, dentro de los treinta días siguientes a su publicación.

En el caso de decretos de convocación a plebiscito, la cuestión puede ser formulada por la Cámara de Diputados o el Senado, dentro del plazo de diez días contados desde la fecha de publicación del decreto que fija el día de la consulta plebiscitaria. 
En el caso de dictarse decretos inconstitucionales o decretos promulgatorios de un texto de ley diverso del que constitucionalmente corresponda, cualquiera de las dos Cámaras, o una cuarta parte, al menos, de los Diputados o Senadores en ejercicio pueden solicitar el pronunciamiento del Tribunal Constitucional dentro del plazo de treinta días de la publicación o notificación del texto impugnado.

El proyecto de Ley Orgánica Constitucional del Tribunal Constitucional establece que admitido a tramitación el requerimiento, debe ponerse en conocimiento del Contralor General de la República.

Finalmente, el proyecto de LOC del Tribunal Constitucional consagra expresamente lo que la propia Constitución establece respecto de los efectos de la sentencia que acoja el reclamo: el decreto queda sin efecto de pleno derecho. No tiene, en consecuencia, el efecto derogatorio de la ley.

\section{El control reparador de decretos de convocatoria a plebiscito de reforma cons- titucional.}

A simismo, conoce de acuerdo al artículo $93 \mathrm{~N}^{\circ}$ 5, en control preventivo facultativo sobre la constitucionalidad de los decretos de convocatoria a plebiscito de reforma constitucional. La legitimación activa es limitada al Senado o a la Cámara de Diputados, dentro del plazo de diez días contados desde la fecha de publicación del decreto que fije la consulta plebiscitaria.

El objetivo de este control es evitar que la autoridad gubernamental abuse de su potestad redactando preguntas tendenciosas o manipuladoras de la ciudadanía, posibilitando al Tribunal Constitucional corregir tales anomalías, estableciendo en su resolución el texto definitivo de la consulta plebiscitaria, cuando ello fuere procedente.

El texto constitucional faculta al Tribunal Constitucional para modificar el día de realización del plebiscito, si al dictarse la sentencia faltaren menos de treinta días para la realización del mismo, debiendo establecer una nueva fecha comprendida entre los treinta y sesenta días siguientes al fallo.

c) El control de constitucionalidad en materia de conflicto de competencias. En efecto, todo conflicto entre órganos constitucionales, constituye un conflicto constitucional, que pone en jaque el sistema con el que la Constitución organiza la distribución de funciones y competencias. Los tribunales o Cortes Constitucionales son, sin lugar a dudas, los órganos más idóneos para asumir la resolución de estos conflictos o contiendas de atribuciones o de competencias entre órganos del poder público, en virtud de ser guardianes de la preservación de la repartición de competencias y del equilibrio orgánico establecido por la Constitución, como asimismo, intérprete supremo de la Constitución, siendo el órgano jurídico técnico que cuenta con mayor legitimidad para ello.

Estos conflictos de competencias o atribuciones entre órganos estatales, regionales o locales pueden ser conflictos positivos o negativos. El conflicto positivo es aquel 
que es producto de una determinada actuación de un órgano que se atribuye una competencia que otro órgano entiende que le pertenece, presentándose así un conflicto entre dos órganos que consideran que son los legitimados para adoptar el acto 0 resolución, siendo el órgano requirente el que se considere privado del ejercicio de su competencia o atribución. Por otra parte, es posible también la existencia de un conflicto negativo producto de la pasividad de un órgano cuya inactividad impide el ejercicio normal de las competencias de otro órgano, los cuales también pueden ser conocidos y resueltos por el Tribunal Constitucional por el procedimiento previsto para las hipótesis de indebida asunción de atribuciones, donde el órgano requirente será aquel que se considera impedido de ejercer su competencia por la inactividad del órgano requerido.

En estos casos estamos en un proceso inter partes, donde el Tribunal Constitucional determina definitivamente a qué órgano corresponde la titularidad de la competencia o atribución controvertida. La finalidad de acudir al Tribunal Constitucional es la de precisar la titularidad de la competencia o atribución, como asimismo, en su caso, anular las normas, resoluciones o actos viciados de incompetencia que haya generado el conflicto.

Para que exista un conflicto o contienda de competencia es necesario que los sujetos involucrados cuenten con legitimidad para plantear la acción, los cuales son, por regla general, los órganos constitucionales, los gobiernos regionales, departamentales o locales. Asimismo, es necesario que el conflicto verse sobre una dimensión constitucional, en la medida que se trate de competencias o atribuciones que gocen de reconocimiento en la Carta Fundamental o sean parte del bloque constitucional, al que se integran, en ciertos casos, los contenidos de leyes orgánicas constitucionales referentes a la materia. Es necesario precisar que esas competencias pueden ser exclusivas, concurrentes o compartidas, como asimismo pueden ser delegadas.

Lo que se busca a través de este tipo de proceso constitucional es que los órganos respeten el orden de competencias y atribuciones determinado por la Constitución y la normativa que pudiere integrar el bloque de constitucionalidad, como asimismo, pronunciarse sobre una eventual norma, resolución o acto, emitido por un órgano sin competencia para ello.

En Chile, hasta la reforma constitucional 2005, las contiendas de competencias entre órganos políticos o administrativos y tribunales de justicia eran resueltas por el Senado, de acuerdo a lo dispuesto en el artículo 49 № 3 de la Constitución, o por la Corte Suprema de Justicia, de acuerdo a lo previsto en el artículo 79 inciso final de la Carta Fundamental. La reforma constitucional de 2005 atribuye al Tribunal Constitucional la potestad en materia de contiendas de competencias que detenta hasta dicho momento la Corte Suprema de Justicia de acuerdo a los artículos 49 № 3 y 79 inciso final de la Constitución, todo ello de acuerdo al nuevo numeral $12^{\circ}$ del artículo 82 , el cual precisa como nueva competencia: "Resolver las contiendas de competencia que se susciten entre las autoridades políticas o administrativas y los tribunales de justicia;". 
Sobre la atribución de conocer y resolver contiendas de competencia, el proyecto de LOC del Tribunal Constitucional en trámite parlamentario, parte por establecer las dos causales que permiten formular el problema ante el Tribunal Constitucional: que un órgano alegue invasión de sus atribuciones o que un órgano alegue que carece de competencias sobre un asunto determinado.

La legitimación activa le corresponde al órgano que se siente invadido en sus competencias o que considera que la competencia no le corresponde, debiendo presentar su petición por escrito ante el Tribunal.

\section{d) Las competencias residuales del Tribunal Constitucional.}

La competencia en materia sancionatoria de conductas antidemocráticas de partidos o movimientos políticos y de las personas responsables de ellas.

El Tribunal Constitucional chileno, en forma similar al Tribunal Constitucional alemán, conoce y resuelve sobre los actos o conductas de las organizaciones, movimientos y partidos políticos que atenten contra los principios básicos del régimen democrático y constitucional, utilicen la violencia como método de acción política o procuren el establecimiento de un sistema totalitario. Asimismo, debe resolver sobre las acciones que puede presentar cualquier ciudadano (acción popular) respecto de las personas que hayan sido responsables en los hechos que motivaron la declaración de inconstitucionalidad de una organización política.

Este tipo de atribución de los tribunales constitucionales con matices se ha incrementado con la implementación de los tribunales de Europa Central y Oriental, como es el caso de Albania, Armenia, Azerbaijan, Croacia, Eslovenia, Georgia, Moldavia, Polonia, República Checa, República Eslovaca, Rumania, entre otros.

El artículo $93 \mathrm{~N}^{\circ} 10^{\circ}$ precisa: "Declarar la inconstitucionalidad de las organizaciones y de los movimientos o partidos políticos, como asimismo la responsabilidad de las personas que hubieran tenido participación en los hechos que motivaron la declaración de inconstitucionalidad, en conformidad a lo dispuesto en los párrafos sexto, séptimo y octavo del № 150 del artículo 19 de esta Constitución.

Sin embargo, si la persona afectada fuera el Presidente de la República o el Presidente electo, la referida declaración requerirá, además, el acuerdo del Senado adoptado por la mayoría de sus miembros en ejercicio".

Las competencias para resolver las inhabilidades e incompatibilidades constitucionales y legales que afectan a una persona para desempeñar el cargo de Ministro de Estado, permanecer en el cargo o desempeñan otras funciones simultáneamente.

Esta competencia está contemplada en el artículo $93 \mathrm{~N}^{\circ} 13$ de la Carta Fundamental, sin que hasta ahora haya sido utilizada dentro de los dieciséis años de vigencia transcurridos desde el restablecimiento del sistema democrático constitucional. 


\begin{abstract}
Las competencias en materia de sobre las inhabilidades, incompatibilidades y causales de cesación en el cargo de los parlamentarios, como asimismo pronunciarse sobre la inhabilidad invocada por un parlamentario en los términos del inciso final del artículo 60 de la Constitución y pronunciarse sobre su renuncia al cargo.

Esta competencia está establecida en el artículo 93 Nos 14 y 15 de la Constitución.
\end{abstract}

La competencia de informar al Senado sobre la inhabilidad del Presidente de la República o del Presidente Electo cuando un impedimento físico o mental lo inhabilita para el ejercicio de sus funciones.

Esta competencia está establecida en el artículo 93 №11), materia que debe ser decidida por el Senado de acuerdo al artículo 53 número 7 de la Constitución, considerando dicho informe.

e) Consideraciones finales. Sobre competencias del Tribunal Constitucional. Las reformas en materias de competencias del Tribunal Constitucional como lo dispuso la propia Carta Fundamental reformada en su disposición decimosexta transitoria, ${ }^{29}$ han entrado en vigencia el 26 de febrero de 2006, seis meses después de publicada la reforma constitucional a través de la ley $N^{\circ} 20.050$ de reforma constitucional publicada en el Diario Oficial el 26 de agosto de 2005.30

De esta forma las nuevas competencias del Tribunal Constitucional en materia de control de inaplicabilidad por inconstitucionalidad, el control de inconstitucionalidad de preceptos legales, el control de constitucionalidad de preceptos legales con efectos erga omnes, el control de constitucionalidad de autos acordados de los tribunales superiores de Justicia y del Tribunal Constitucional, el control preventivo obligatorio sobre tratados internacionales que versen sobre materias propias de ley orgánica constitucional en el derecho interno, como asimismo, la nueva potestad de resolver los conflictos de competencia, el Tribunal Constitucional empezó a ejercerlas en marzo de 2006, sin que aún se haya aprobado la reforma de la Ley Orgánica Constitucional del Tribunal Constitucional, la que espera terminar su proceso de aprobación parlamentaria en el mes de agosto de 2008, más de dos años y medio después de que el Tribunal inició el ejercicio de sus nuevas competencias.

La reforma constitucional analizada constituye un avance significativo en el fortalecimiento de la fuerza normativa de la Constitución y en el control de constitucionalidad, ahora con un solo parámetro de control, el cual además tiene carácter obligatorio para todos los órganos estatales. Se robustece el Tribunal Constitucional, sus competencias y su rol de supremo defensor del orden democrático constitucional.

\footnotetext{
29 La disposición decimosexta transitoria del nuevo texto constitucional establece: "Las reformas introducidas al Capítulo VIII entrarán en vigor seis meses después de la publicación de la presente reforma constitucional, con excepción de lo regulado en la disposición décimocuarta".

30 Ver el nuevo texto constitucional refundido y sistematizado en: www.cecoch.cl/materiales
} 
Sin embargo, pese a la significativa potencialización del Tribunal Constitucional, el constituyente instituido no quiso transferirle la resolución de contiendas de competencias entre autoridades políticas o administrativas y los tribunales superiores de justicia, la cual fue retenida por el Senado de la República, de acuerdo al artículo 53 $N^{\circ} 3$ de la Constitución, estando obviamente mejor posesionado el Tribunal Constitucional para resolver esta materia que el Senado que tenderá a resolver el asunto con criterios más políticos que jurídicos. Asimismo, se mantiene un ámbito en el que no llega la fuerza normativa de la Constitución, como ocurre con los reglamentos parlamentarios, los cuales no son sólo "interna corporis", sino que regulan el procedimiento de acusación constitucional, el cual podría eventualmente vulnerar el derecho constitucional al debido proceso, por ejemplo.

Por último, la observación más importante es que el constituyente derivado no quiso entregarle al Tribunal Constitucional el amparo extraordinario de derechos ni la revisión de sentencias de tribunales ordinarios o especiales violatorias de derechos fundamentales, lo que deja a nuestro Tribunal Constitucional sin una dimensión importante del constitucionalismo contemporáneo, como es la protección constitucional efectiva de los derechos fundamentales, aun cuando dicho control se filtrará en la práctica a través del control concreto de constitucionalidad de preceptos legales.

\section{CONSIDERACIONES FINALES}

Chile ha recuperado un régimen constitucional democrático, eliminando los últimos enclaves autoritarios con la reforma constitucional de 2005. Uno de los aspectos que genera aún un fuerte debate es la modificación del sistema electoral binominal, sin que hasta ahora se haya producido el necesario consenso para su modificación.

En una perpectiva de futuro, consideramos que se producirá un nuevo debate nacional sobre el eventual cambio de tipo de gobierno desde un presidencialismo puro hacia tipos de gobierno con mayor nivel de flexibilidad, siendo una alternativa válida el sistema semipresidencial, tema que es objeto de análisis por una Comisión Especial de la Cámara de Diputados en este segundo semestre de 2008. A simismo, en el ámbito de la profundización democrática, la línea de avance se desarrolla en el paso de un régimen de descentralización administrativa con gobiernos regionales, cuyas autoridades deben ser electas por los respectivos cuerpos políticos regionales, desvinculando el ejecutivo regional del órgano de gobierno interior en la región nombrado por el Presidente de la República, como asimismo, estableciendo una ley de rentas regionales que posibilite a tales gobiernos el ejercicio adecuado y autónomo de sus competencias las que deben ser revisadas. A simismo, se avanza en la introducción de autonomías especiales en determinados territorios insulares. Se debate la introducción de algunos mecanismos de democracia semidirecta como la iniciativa popular de ley y eventuales plebiscitos revocatorios. 


\section{BIBLIOGRA FÍA}

Andrade Geywitz, Carlos. Reforma de la Constitución Política de la República de Chile. Editorial Jurídica de Chile. Santiago, Chile, 1991.

Andrade Geywitz, Carlos, "Tribunal Constitucional" en Cuadernos de A nálisis Jurídico № 31, Ed. Facultad de Derecho, Universidad Diego Portales, Santiago, Chile, 1996.

Arriagada, Genaro. Por la razón o la fuerza, Chile bajo Pinochet. Ed. Sudamericana. Santiago, Chile. 1998.

BAZÁN, Víctor, Jurisdicción constitucional y control de constitucionalidad de los tratados internacionales. Un análisis de derecho comparado, Editorial Porrúa, México, 2003.

Blanc, N.; Nogueira, H.; Pfeffer, E., y Verdugo, M. La Constitución Política de la República de Chile. Valparaíso, Chile. Ed. Centro de Estudios y A sistencia Legislativa. Universidad Católica de Valparaíso, 1990.

Bertelsen, Raúl y otros, “Función del Tribunal Constitucional de 1980" en Estudios Públicos No 27, Santiago, Chile, 1987.

Bulnes Aldunate, Luz. "La reforma constitucional al Congreso Nacional", en Nogueira Alcalá, Humberto (Coord.). La Constitución reformada de 2005. Centro de Estudios Constitucionales de Chile. Ed. Librotecnia, Santiago, 2005.

Bulnes A ldunate, Luz. "Los estados de excepción frente a la reforma constitucional”, en Zúñiga, Francisco (coord.). Reforma Constitucional. Ed. LexisNexis, Santiago, 2005.

Cañas K., Enrique. Proceso Político en Chile. 1973-1990. Ed. Andrés Bello. Santiago, Chile.

Carey, John M. y Siavelis, Peter. "El seguro para los subcampeones electorales y la sobrevivencia de la Concertación", en Revista Estudios Públicos 90 (Otoño). 2003.

Carrasco Delgado, Sergio. "La Constitución Política de la República de Chile y su reforma", en Zúñiga, Francisco (coord.). Reforma Constitucional. Ed. LexisNexis, Santiago, 2005.

Colom во C., Juan. "Tribunal Constitucional: integración, competencia y sentencia”, en Zúñiga, Francisco (coord.). Reforma Constitucional. Ed. LexisNexis, Santiago, 2005, pp. 551-592.

Cordero Q., Eduardo. “La facultad fiscalizadora de la Cámara de Diputados”, en Zúñiga, Francisco (coord.). Reforma Constitucional. Ed. LexisNexis, Santiago, 2005, pp. 507-526.

Cum plido Cereceda, Francisco, "Tribunal Constitucional y control ideológico", en La Revista de Derecho № 1, Ed. Facultad de Derecho, Universidad Central de Chile, 1989.

Cum plido Cereceda, Francisco. “Reforma Constitucional y régimen político”, en Zúñiga, Francisco (coord.). Reforma Constitucional. Ed. LexisNexis, Santiago, 2005.

Fernández, Mario. “El Sistema Electoral Chileno. Dilucidando Equívocos y Adaptando Fórmulas", en A gustín Squella y Osvaldo Sunkel (eds. ), Democratizar la Democracia. Reformas Pendientes, Ed. LOM, Santiago, 2000.

GuzmÁn, Eugenio. "Reflexiones sobre el sistema binominal", Revista Estudios Públicos 51 (invierno), 1993, pp. 303-324. 
Huneeus M., Carlos. El régimen de Pinochet. Editorial Sudamericana. Santiago, Chile, 2000.

Llanos M ansilla, Hugo. “Los tratados y la reforma constitucional”, en Nogueira Alcalá, Humberto (Coord.). La Constitución reformada de 2005. Centro de Estudios Constitucionales de Chile. Ed. Librotecnia, Santiago, 2005.

M artínez EstaY, José Ignacio. "Recurso de inaplicabilidad, Tribunal Constitucional y juez ordinario en la reforma constitucional", en Nogueira A Icalá, Humberto (Coord.). La Constitución reformada de 2005. Centro de Estudios Constitucionales de Chile. Ed. Librotecnia, Santiago, 2005.

NAVIA, Patricio y CABEZAS, José M iguel. "Efecto del sistema binominal en el número de candidatos y de partidos en elecciones legislativas en Chile, 1989-2001", Revista Política. Vol. 45 (primavera), pp. 29-52, 2005.

Nogueira A lcalá, Humberto. "Introducción a los Sistemas Electorales y al Sistema Electoral Chileno". Serie Documentos de Estudios N 3 . Corporación Participa. Santiago de Chile, 1992.

Nogueira Alcalá, Humberto. Regímenes Políticos Contemporáneos. Editorial Jurídica de Chile. Santiago, 1993.

Nogueira AlCalÁ, Humberto, "El Tribunal Constitucional chileno", en Lecturas Constitucionales Andinas № 1, Ed. Comisión A ndina de Juristas, Lima, Perú, 1991.

Nogueira AlcalÁ, Humberto, "La democracia, el orden constitucional democrático y las reglas de su modificación", en XX Jornadas de Derecho Público, Tomo I, Ed. Edeval, Valparaíso, 1990.

NogueiRa AlCALÁ, Humberto. "El control represivo concreto y abstracto de inconstitucionalidad de leyes en la reforma de 2005 de las competencias del Tribunal Constitucional y los efectos de sus sentencias", en Nogueira A lcalá, Humberto (Coord.). La Constitución reformada de 2005. Centro de Estudios Constitucionales de Chile. Ed. Librotecnia, Santiago, 2005.

Nogueira A LCALÁ, Humberto. "Aspectos fundamentales de la reforma constitucional de 2005 en materia de tratados internacionales", en Nogueira Alcalá, Humberto (Coord.). La Constitución reformada de 2005. Centro de Estudios Constitucionales de Chile. Ed. Librotecnia, Santiago, 2005, pp. 381-404.

Nogueira Alcalá, Humberto (Coord.). La Constitución reformada de 2005. Centro de Estudios Constitucionales de Chile. Ed. Librotecnia, Santiago, 2005.

Nogueira Alcalá, Humberto. Derechos fundamentales y garantías constitucionales. Tomo I. Ed. Librotecnia, 2007.

PASTOR, Daniel. "Origins of the Chilean Binominal Election System", en Revista de Ciencia Política. Vol. XXIV Nº 1, 2004.

PeÑa TorRes, M arisol. "Reformas al sistema de remoción de los comandantes en jefe de las Fuerzas Armadas y a la composición y atribuciones del Consejo de Seguridad Nacional", en Nogueira Alcalá, Humberto (Coord.). La Constitución reformada de 2005. Centro de Estudios Constitucionales de Chile. Ed. Librotecnia, Santiago, 2005.

PÉrez LISICIC, Rodrigo. "Senado y reforma constitucional: Modificaciones al artículo 45 de la Constitución de 1980", en Zúñiga, Francisco (coord.). Reforma Constitucional. Ed. LexisNexis, Santiago, 2005. 
Ríos A., Lautaro, "El control difuso de constitucionalidad de la ley en la República de Chile" en Revista lus et Praxis, año 8 № 1, Ed. Universidad de Talca, Chile, 2002, pp. 389-418.

Ríos Álvarez, Lautaro, "La Justicia Constitucional en Chile" en La Revista de Derecho № 1, Ed. Facultad de Derecho, Universidad Central, Santiago, Chile, 1988.

Ríos Á lvarez, Lautaro. "El nuevo Tribunal Constitucional”, en Zúñiga, Francisco (coord.). Reforma Constitucional. Ed. LexisNexis, Santiago, 2005.

Rios Álvarez, Lautaro. "Los estados de excepción constitucionales en una perspectiva humanista", en Nogueira Alcalá, Humberto (Coord.). La Constitución reformada de 2005. Centro de Estudios Constitucionales de Chile. Ed. Librotecnia, Santiago, 2005.

Rivera, Teodoro, "Función y composición del Tribunal Constitucional de 1980", Documento de Trabajo № 74, Centro de Estudios Públicos, Santiago, Chile, 1986.

SAenger GianonI, Fernando y Jiménez LoosLI, Fernando. "Los Estados de excepción constitucional", en Zúñiga, Francisco (coord.). Reforma Constitucional. Ed. LexisNexis, Santiago, 2005.

Scully, Timothy, y Valenzuela, Samuel. "De la Democracia a la Democracia. Continuidad y Variaciones en las Preferencias del Electorado y en el Sistema de Partidos en Chile", en Revista Estudios Públicos, N 51, Invierno de 1993.

SIAVELIS, Peter. Continuity and change in the chilean party system. Comparative Political Studies 30, 6, December, 1997, pp. 651-674.

Silva Bascuñán, Alejandro y Silva Gallinato, María Pía, "La misión del Tribunal Constitucional", en XXIV Jornadas de Derecho Público, Revista Chilena de Derecho, Ed. Facultad de Derecho, Pontificia Universidad Católica de Chile, Santiago, Chile, 1993.

SIIVA BAscuñán, Alejandro, Tratado de Derecho Constitucional, Tomo IX, Editorial Jurídica de Chile, Santiago, 2003.

Valenzuela, Samuel. "Orígenes y Transformación del Sistema de Partidos en Chile", en Revista Estudios Públicos N 58, otoño de 1995.

Valenzuela, Arturo y Siavelis, Peter. "Ley electoral y estabilidad democrática: un ejercicio de simulación para el caso de Chile". Revista Estudios Públicos 43 (invierno), 1991.

VIAL, Gonzalo (Ed.). A nálisis crítico del régimen militar. Universidad Finis Terrae. Santiago, Chile, 1998.

ZÚNIIGA URBINA, Francisco. Elementos de jurisdicción constitucional, Tomo II, Ed. Universidad Central de Chile, Santiago, 2002, pp. 39-124.

ZÚÑIGA URBINA, Francisco. "Control concreto de constitucionalidad: recurso de inaplicabilidad y cuestión de constitucionalidad en la reforma constitucional", en Nogueira Alcalá, Humberto (Coord.). La Constitución reformada de 2005. Centro de Estudios Constitucionales de Chile. Ed. Librotecnia, Santiago, 2005.

ZúNIIGA UrBINA, Francisco (coord). Reforma Constitucional. Ed. LexisNexis, Santiago, 2005.

ZÚNIIGA URBINA, Francisco. "Reforma del capítulo XV: 'Reforma de la Constitución', en Zúñiga, Francisco (coord.). Reforma Constitucional. Ed. LexisNexis, Santiago, 2005.

Zúñiga URBina, Francisco y Vega Méndez, Francisco. "Control político de la Cámara de diputados en la reforma constitucional", en Nogueira Alcalá, Humberto (Coord.). La Constitución reformada de 2005. Centro de Estudios Constitucionales de Chile. Ed. Librotecnia, Santiago, 2005. 